\title{
Journal of Soils and Sediments \\ Effects of Superdispersant-25 on the sorption dynamics of naphthalene and phenanthrene in marine sediments --Manuscript Draft--
}

\begin{tabular}{|c|c|}
\hline Manuscript Number: & JSSS-D-18-00190R2 \\
\hline Full Title: & $\begin{array}{l}\text { Effects of Superdispersant- } 25 \text { on the sorption dynamics of naphthalene and } \\
\text { phenanthrene in marine sediments }\end{array}$ \\
\hline Article Type: & Research Article \\
\hline Section/Category: & Sediments \\
\hline Corresponding Author: & $\begin{array}{l}\text { Luis Jose Perez Calderon } \\
\text { University of Aberdeen } \\
\text { Aberdeen, Scotland UNITED KINGDOM }\end{array}$ \\
\hline \multicolumn{2}{|l|}{$\begin{array}{l}\text { Corresponding Author Secondary } \\
\text { Information: }\end{array}$} \\
\hline Corresponding Author's Institution: & University of Aberdeen \\
\hline \multicolumn{2}{|l|}{$\begin{array}{l}\text { Corresponding Author's Secondary } \\
\text { Institution: }\end{array}$} \\
\hline First Author: & Luis Jose Perez Calderon \\
\hline \multicolumn{2}{|l|}{ First Author Secondary Information: } \\
\hline \multirow[t]{5}{*}{ Order of Authors: } & Luis Jose Perez Calderon \\
\hline & Lloyd Douglas Potts \\
\hline & Alejandro Gallego \\
\hline & James Anderson \\
\hline & Ursula Witte \\
\hline \multicolumn{2}{|c|}{ Order of Authors Secondary Information: } \\
\hline \multicolumn{2}{|l|}{ Funding Information: } \\
\hline Abstract: & $\begin{array}{l}\text { Purpose: The present study evaluated the effects of Superdispersant-25 (SD25), a } \\
\text { commercial dispersant stockpiled in the United Kingdom for oil spill response, on the } \\
\text { sorption dynamics of two polyaromatic hydrocarbons, naphthalene (NAP) and } \\
\text { phenanthrene (PHE), in sediment-seawater systems using three sediments near } \\
\text { hydrocarbon exploration areas in the Faroe-Shetland Channel and North Sea. } \\
\text { Materials and methods: Batch experiments were conducted to evaluate the effects of } \\
\text { SD25 on the solubility (analysed by gas chromatography), distribution coefficients and } \\
\text { desorption hysteresis of NAP and PHE separately as well as SD25 in the three } \\
\text { sediments (analysed by UV-vis spectroscopy and surface tension measurements, } \\
\text { respectively). } \\
\text { Results and discussion: The results revealed that SD25 readily adsorbed to all } \\
\text { sediment types but did not desorb from silty loam. SD25 application increased the } \\
\text { solubility in seawater of PHE but not of NAP. Adsorbed SD25 increased the distribution } \\
\text { coefficients of both polyaromatic hydrocarbons in sand but not silty loam and the } \\
\text { solubilising effect of SD25 appeared to drive increased adsorption of PHE rather than } \\
\text { sediment-adsorbed SD25 concentration. } \\
\text { Conclusions: The findings highlight the influence of SD25 application on the sorption } \\
\text { dynamics of NAP and PHE in marine sediments from areas near hydrocarbon } \\
\text { exploration and production regions. An understanding of these interactions may aid } \\
\text { responders in the decision-making process of dispersant application in the event of a } \\
\text { spill as seabed characteristics affect oil-dispersant-sediment interactions. }\end{array}$ \\
\hline Response to Reviewers: & $\begin{array}{l}\text { Thank you for the comments on the latest version of the manuscript. As in the first } \\
\text { revision, I've enclosed replies in a separate file for ease of visualisation. }\end{array}$ \\
\hline
\end{tabular}


Ref.: Ms. No. JSSS-D-18-00190R1

Replies to reviewers' and editors' comments

Comments by reviewers and editors are shown in italics and responses in bold.

Effects of Superdispersant-25 on the sorption dynamics of naphthalene and phenanthrene in marine sediments

Journal of Soils and Sediments

Dear Mr Perez Calderon,

We thank you for submitting your manuscript to the Journal of Soils and Sediments.

The editors of JSS have now had time to assess your manuscript and have made the following recommendations and comments.

They recommend a minor revision.

Please consider these comments carefully. If you feel that you are able to address these comments and suggestions sufficiently, then JSS would be happy to consider submission and assessment of a revised manuscript. Please be aware that we may ask the original and/or new referees to review the revised manuscript, although the final decision rests with the Editor-in-Chief.

For your guidance, the review reports are appended below. In addition, please address the following:

1) Line 337 - change to "(Heath and Bailey 1994)"

This has now been updated (line 337).

2) For the bibliography - please only use a capital for the first letter of the first word of article titles.

References have now been updated to include only the first letter of the first word in capital (except where there are names of places or rigs e.g. Faroe, Deepwater Horizon). An exception in the reference list is "ggplot2: elegant graphics for data analysis", in which the first letter of the title is lower case as this is the name of the software.

3) For the bibliography - please give the full range of pages not just the first page.

Page ranges have now been included for references where they were missing. Note some references are software or are articles with a single page. In these cases, no page number or a single page number is reported, respectively.

4) Several references need more details (such as the publisher, report number, etc) - for example Dixon (2014), Fingas (2002), Florida State University (2013), Heath and Bailey (1994), USEPA (2008).

These references, and others, have been edited to include the requested information (reference list).

5) In the case of the Dixon reference, to me it looks like the report is from 2015 and "2014" should be added to the end of the title. Plus you should add the name of the publisher "Advisory Committee on Protection of the Sea, Cambridge, UK"

This reference has now been updated (line 46 and reference list).

6) There is still a problem with the reference on line 511-512 and the text on line 142-143, I suggest that you remove the text on line 511-512 and instead incorporate it on line 142-143 (perhaps in brackets).

The reference has been included in brackets and removed from the Reference list at the end of the document (lines 141-143). 


\section{7) Line 341- please change to "(Figs 5,6)"}

\section{This has now been updated (line 344).}

If you decide to revise the paper, please submit a list of changes or a rebuttal against each point raised by the editor and reviewers when you submit the revised manuscript.

We also request you to highlight any changes made to the revised version of your manuscript to make it easier for the reviewers to check whether their comments have been addressed appropriately. Please make sure to submit your editable source files (i.e. Word, TeX).

Your revision is due by 18 Oct 2018.

To submit a revision, go to https://jsss.editorialmanager.com/ and log in as an Author. You will see a menu item called 'Submissions Needing Revision'. You will find your submission record there.

We thank you for considering JSS as an outlet for your work.

With kind regards,

Philip N. Owens

Editor-in-Chief

Journal of Soils and Sediments

Reviewers' comments:

Thank you for your detained update on your article. In the future it would make evaluating your revisions easier if you state the line numbers in the revised document rather than just stating that it has been addressed in the discussion for example. I was able to find them with your track-changes, but page numbers would be appreciated by any editor in the future.

Apologies, thank you for the advice. Line comments have been included in this revision of the manuscript.

I feel that this paper is now acceptable for publication within JSS following a suggested 2 minor adjustments

1. Please add one line justifying as to why 20 degrees was used. This can be similar to your response to Reviewer \#2.

This has been included in the Materials and methods section (lines 166-169).

2. Please change your reference of Florida State University 2014. This reference is not easily obtainable by readers and should be replaced with a referenceable paper/document. There are many documents on Exopolymers with regard to flocculation, marine snow and interaction with contaminants.

This reference has been updated by an easier-to-find one (line 410 and reference list):

Passow, U. (2016) 'Formation of rapidly-sinking, oil-associated marine snow', Deep Sea Research Part II: Topical Studies in Oceanography. Elsevier, 129, pp. 232-240. doi: 10.1016/j.dsr2.2014.10.001. 


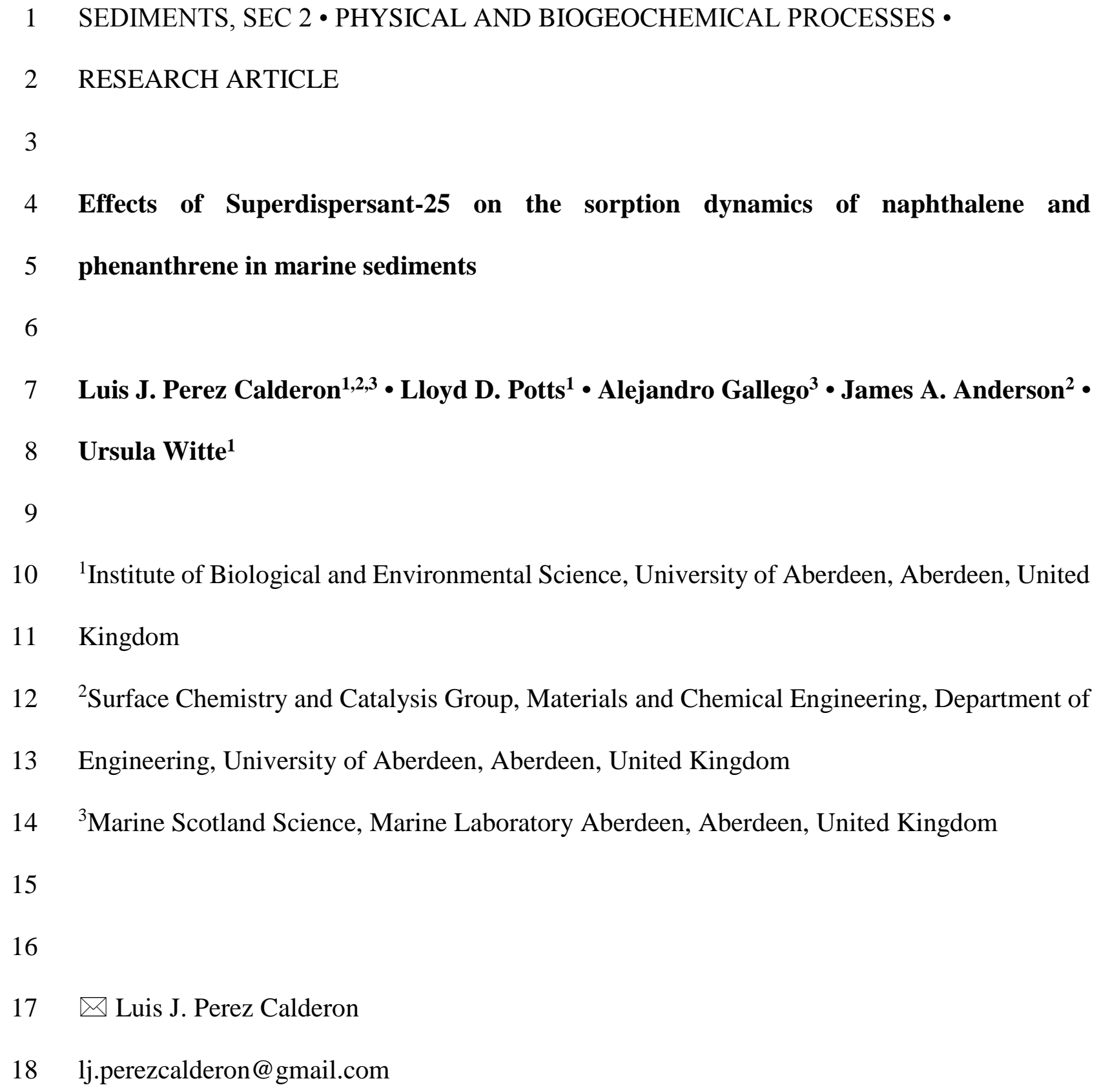




\section{Abstract}

21 Purpose: The present study evaluated the effects of Superdispersant-25 (SD25), a commercial

22 dispersant stockpiled in the United Kingdom for oil spill response, on the sorption dynamics

23 of two polyaromatic hydrocarbons, naphthalene (NAP) and phenanthrene (PHE), in sediment-

24 seawater systems using three sediments near hydrocarbon exploration areas in the Faroe-

25 Shetland Channel and North Sea.

26 Materials and methods: Batch experiments were conducted to evaluate the effects of SD25 on

27 the solubility (analysed by gas chromatography), distribution coefficients and desorption

28 hysteresis of NAP and PHE separately as well as SD25 in the three sediments (analysed by

29 UV-vis spectroscopy and surface tension measurements, respectively).

30 Results and discussion: The results revealed that SD25 readily adsorbed to all sediment types 31 but did not desorb from silty loam. SD25 application increased the solubility in seawater of 32 PHE but not of NAP. Adsorbed SD25 increased the distribution coefficients of both 33 polyaromatic hydrocarbons in sand but not silty loam and the solubilising effect of SD25 34 appeared to drive increased adsorption of PHE rather than sediment-adsorbed SD25 35 concentration.

36 Conclusions: The findings highlight the influence of SD25 application on the sorption 37 dynamics of NAP and PHE in marine sediments from areas near hydrocarbon exploration and 38 production regions. An understanding of these interactions may aid responders in the decision39 making process of dispersant application in the event of a spill as seabed characteristics affect 40 oil-dispersant-sediment interactions.

41 Keywords Dispersant $\bullet$ Naphthalene $\bullet$ Oil spill $\bullet$ PAHs $\bullet$ Phenanthrene $\bullet$ Sediment $\bullet$ Solubility 42 - Sorption 


\section{Introduction}

44 Hydrocarbon exploration and extraction in the United Kingdom continental shelf has been ongoing for approximately 40 years. In 2014 alone, a total of 30 oil spills (>2 t) have taken place in the United Kingdom Continental Shelf (Dixon 2015). More recently, the BP Clair spill resulted in the release of $95 \mathrm{t}$ of crude oil into the North Sea in 2016 (Webster et al. 2016). Oil releases to the marine environment are ecologically undesirable due to the persistence of oil and the presence of toxic components in crude oil such as polyaromatic hydrocarbons (PAHs, hereafter) which are carcinogenic to humans, can bioaccumulate in marine organisms and persist in the environment for years (Mearns et al. 2010).

During the Deepwater Horizon (DwH, hereafter) oil spill (2010) 4.9 million barrels of oil were released to the Gulf of Mexico from the Macondo well MC252 (Beyer et al. 2016) and 4$14.4 \%$ of the oil settled on the deep seabed (Chanton et al. 2015). Contact of oil with sediment, particularly coastal sediments, is highly undesirable because it can cause negative environmental impacts if oil is stranded in sensitive areas such as salt marshes or on beaches for human use (Hayworth et al. 2015; Pietroski et al. 2015). Dissolved and dispersed oil in the marine environment can adsorb onto suspended particulate matter such as sediment particles, organic debris or actual organisms to form aggregates (Gong et al. 2014a). Particle size can influence the amount of oil adsorbed as a consequence of its relative surface area (Pignatello 1998). Fine sediments, with larger surface area per unit volume, can take up more oil than coarser ones, with lower surface area. Hydrophobic pollutants readily adsorb onto organic matter in sediments, organic carbon (OC) content has been shown to be the main driver of organic pollutant sorption to sediments (Xing et al. 1996). Therefore, OC-rich sediments are expected to uptake more organic pollutants than sediments low in OC. Other variables that affect sorption of organic compounds onto sediments include temperature, salinity and pressure (Piatt et al. 1996; Marini and Frapiccini 2013; Zhao et al. 2015). Oil-sediment aggregation can influence oil fate in the marine environment. Oil-sediment aggregates can be transported to the seabed by sedimentation or be mobilised horizontally by currents, waves and winds to locations far from the oil spill source (Bandara et al. 2011).

Oil spill models are tools used in prevention and response operations in the oil and gas industry to predict the trajectories and fates of spilled oil in the environment (Reed et al. 1999). A component of oil spill models is the interaction of oil with sediment particles and their subsequent fate. To our knowledge, the Oil Spill Contingency and Response (OSCAR) model 
uses the algorithms from Bandara et al. (2011). This is an algorithm but considers oil droplets as a single pollutant, and as such does not capture the distribution of single component interactions. A useful property to implement in these models is the water-sediment distribution coefficients $\left(K_{\mathrm{D}}\right.$; volume/mass). The coefficient represents the affinity of a pollutant for a particular sediment and is defined as (Matthies 2011):

$$
K_{D}=\frac{C_{S}}{C_{W}} \quad \text { Eq. } 1
$$

where $C_{\mathrm{S}}$ (mass/mass) and $C_{\mathrm{W}}$ (mass/volume) are the concentrations of a pollutant in sediment and seawater, respectively. $K_{\mathrm{D}}$ coefficients are specific to each pollutant-sediment combination since each sediment has different properties (e.g. particle size distribution, organic matter content, etc.) (Matthies 2011). Further to this, it has been previously shown that $K_{\mathrm{D}}$ can vary by orders of magnitude for a given compound under different environmental conditions (Baes and Sharp 1983). Modelling $K_{\mathrm{D}}$ is difficult due to the large number of variables that influence it and, as such, empirical determination is the most accurate method. Determination of $K_{\mathrm{D}}$ of PAHs is relevant because of their toxicity, recalcitrance and importance in environmental legislation (Yamada et al. 2003; Office of Solid Waste 2008; Mason et al. 2014).

Dispersants are employed during oil spills to lower the interfacial tension between water and oil to facilitate the breaking up of oil slicks into smaller droplets that can then be more rapidly degraded both physically and biologically (Fingas 2002). Following the $D w H$ oil spill, extensive work was undertaken to evaluate the effects of Corexit dispersants (those used during the spill) on oil-suspended particulate matter aggregation (Gong et al. 2014b, a; Zhao et al. 2016). A recent study has shown that different dispersant formulations selectively solubilise and affect the sorption of specific fractions of crude oil (Zhao et al. 2016). For example, Corexit 9500A preferentially dispersed $\mathrm{C}_{12}-\mathrm{C}_{16}$ and $\mathrm{C}_{20}-\mathrm{C}_{28}$ n-alkanes whereas Corexit 9527A favoured $\mathrm{C}_{10}-\mathrm{C}_{20} n$-alkane dispersion. Consequently, the need arises to characterise the effects of other ready-to-use and commercially available dispersants on oil-sediment interactions. Zhao et al. (2015) reported that Corexit 9500A has contrasting effects on the extent to which hydrocarbons adsorb onto sediments; (1) Corexit 9500A increased the solubility of hydrocarbons in seawater and (2) surfactants in Corexit 9500A adsorb to sediment particles and create additional adsorption sites for hydrocarbons.

Given that dispersant application is an important oil spill response strategy that directly affects physicochemical properties of hydrocarbons in the marine environment (Fingas 2002), further 
understanding of its effects on hydrocarbon-sediment interactions is important (Gong et al. 2014a). Over- or underestimation of sorption to sediments may lead to inappropriate choice of resource allocation in the event of an oil spill whereby hydrocarbon uptake by different sediment types may be erroneously estimated.

The aim of this work was to determine the effect of Superdispersant-25 (SD25, hereafter), a dispersant stockpiled in the United Kingdom, on the sorption dynamics of naphthalene and phenanthrene (NAP and PHE, hereafter, respectively) as well as its own sorption dynamics in three sediment types from North Scotland. It was hypothesised that (1) SD25 and PAHs would be taken up to a greater extent by fine than by coarse sediment, (2) an increase in SD25 concentration would favour the partitioning of PHE to the aqueous phase more than that of NAP due to differences in water-solubility and (3) SD25 application would increase PAH adsorption onto sediments by increasing PAH solubility and the creation of additional adsorption sites on the sediment itself by adsorbing to it.

\section{Materials and methods}

\section{$121 \quad 2.1 \quad$ Sediments and artificial seawater}

122 Sediment samples were collected from the top $10 \mathrm{~cm}$ of sediment from the Faroe-Shetland 123 Channel (1000 m; FSC, hereafter) aboard MRV Scotia in May 2014 (61³5.02`N, 4¹4.64’W), 124 Stonehaven Bay (14 m; SB, hereafter) aboard MRV Temora in June 2016 (56 58'18"N, $\left.1252^{\circ} 11^{\prime} 3 " \mathrm{~W}\right)$ and the Ythan estuary (intertidal; YE, hereafter) in December $2016\left(57^{\circ} 18^{\prime} 14^{\prime \prime} \mathrm{N}\right.$, $1261^{\circ} 59 ' 25^{\prime \prime}$ ) (Fig. 1). Sampling methods were maxi-corer (OSIL, United Kingdom), Van Veen 127 grab and manual collection for FSC, SB and YE sediments, respectively. Sediments were 128 autoclaved at $121^{\circ} \mathrm{C}$ for $21 \mathrm{~min}$ at $100 \mathrm{kPa}$ and oven dried at $60^{\circ} \mathrm{C}$ for three days to minimise 129 microbial activity prior to carrying out experiments. Artificial seawater was prepared by adding 130 pre-oven dried (at $130^{\circ} \mathrm{C}$ for $24 \mathrm{~h}$ ) Seamix Artificial Sea Salt (Peacock Salt, United Kingdom) 131 at $3.4 \%$ (mass/volume) to ultra-pure (type 1) water and magnetically stirring for $8 \mathrm{~h}$. 


\subsection{Sediment characterisation}

Sediments were characterised in terms of particle size distribution and carbon content. YE and SB sediments were oven-dried at $105^{\circ} \mathrm{C}$ overnight and sieved through mesh sizes of 2000 , 1000, 500, 250, 120 and $63 \mu \mathrm{m}$. Statistical analyses of particle size distribution were carried out using Gradistat v.8 (Blott and Pye 2001). FSC sediments were oven-dried at $105^{\circ} \mathrm{C}$ overnight and then wet sieved through a $63 \mu \mathrm{m}$ mesh to separate coarse $(>63 \mu \mathrm{m})$ from fine sediment $(<63 \mu \mathrm{m})$. Coarse sediment was then analysed as described above and fine sediment was analysed using the hydrometer method (Ashworth et al. 2001) and statistical analysis of particle size distribution was performed using the Hydrometer Particle Size Calculator (Natural 142 Resources Conservation Service - United States Department of Agriculture Hydrometer 143 Particle Size Calculator - ASTM No. 1).

144 To determine carbon content, sediments were initially oven-dried at $60^{\circ} \mathrm{C}$ for three days. 145 Thereafter, sediments were mechanically milled. Subsequently, total carbon content was 146 determined using a NA2500 elemental analyser (Carlo Erba Instruments). Total OC content was determined by acidifying sediment with $10 \% \mathrm{HCl}$ and oven-dried at $60^{\circ} \mathrm{C}$ for three days and subsequently analysed by elemental analysis. Total inorganic carbon content was determined by difference between total carbon and total OC.

\subsection{Superdispersant-25 measurements and critical micelle concentration determination}

Three independent stock solutions of SD25 in artificial seawater at 100 and $1000 \mathrm{mg} \mathrm{l}^{-1}$ were prepared and equilibrated. Dilutions were performed to obtain solutions at concentrations of 0 , $0.25,5,10,25,50,100,200,300,400,500$ and $1000 \mathrm{mg} \mathrm{l}^{-1}$. Thereafter, seawater surface tension measurements were performed using a tensiometer (White's instruments) fitted with a du Nouy ring to calibrate the response of surface tension to SD25 concentration. The apparent critical micelle concentration was calculated as the inflexion point in seawater surface tension as a function of SD25 concentration, as described elsewhere (Gong et al. 2014). 


\subsection{Effect of Superdispersant-25 on aqueous solubility of PAHs}

161 Saturated solutions of PHE and NAP with increasing SD25 were prepared to assess the

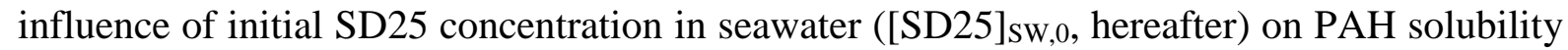
in seawater. Briefly, $200 \mathrm{mg}$ of each PAH were added to separate $70 \mathrm{ml}$ glass vials and stock solutions of seawater and SD25 were mixed to achieve concentrations in the range 0-1000 mg $1^{-1}$ and added to the vials. The mixtures were then equilibrated by magnetic stirring at $20^{\circ} \mathrm{C}$ in complete darkness for three days to ensure dynamic equilibrium. $20^{\circ} \mathrm{C}$ was chosen as past sorption dynamics and sediment hydrocarbon biodegradation literature has been undertaken at this temperature. The experiments were performed in complete darkness to prevent photodegradation of PAHs. After equilibration, solutions were centrifuged in glass centrifuge tubes at $3000 \mathrm{rpm}$ for 10 mins such that suspended PAH is removed from solution and only dissolved PAH remained. 25 and $50 \mathrm{ml}$ of NAP and PHE solutions, respectively, were then sequentially liquid-liquid extracted three times with $10 \mathrm{ml}$ dichloromethane using pristane as an internal extraction standard $\left(100 \mu \mathrm{l}\right.$ at $\left.20 \mu \mathrm{g} \mathrm{ml}^{-1}\right)$. PHE extracts were then evaporated to approximately $5 \mathrm{ml}$ under nitrogen and analysed by gas chromatography with flame ionisation detection. NAP extracts were injected immediately after extraction. Further analysis details can be found elsewhere (Perez Calderon et al. 2018b).

\subsection{Superdispersant-25 uptake by sediments}

Sorption of SD25 by sediments was evaluated in two stages, (1) where SD25 solutions were equilibrated with sediment and (2) where supernatant solutions after equilibration were replaced with clean seawater. These were defined as adsorption and desorption stages, respectively. Pre-treated sediment $(2.5 \mathrm{~g})$ were added to $15 \mathrm{ml}$ Pyrex centrifuge tubes with Teflon-lined caps. $12 \mathrm{ml}$ of SD25 in artificial seawater solutions at concentrations of $0,10,20$, $30,100,175,250,375$ and 500 , and $1000 \mathrm{mg} \mathrm{l}^{-1}$ were prepared and added to the centrifuge tubes. Thereafter, these were incubated in a horizontal shaker at $200 \mathrm{rpm}$ for three days at $20^{\circ} \mathrm{C}$ in complete darkness. Vials were then centrifuged at $3000 \mathrm{rpm}$ for $10 \mathrm{mins}$ and $3 \mathrm{ml}$ of supernatant was sampled to measure surface tension. The remaining supernatant was replaced with artificial seawater and incubated a further three days in complete darkness. Samples were centrifuged again at $3000 \mathrm{rpm}$ for 10 mins and surface tension measurements taken. SD25 concentration was calculated from the calibration curves prepared for the critical micelle 
concentration determination experiment. Measurements were conducted for each sediment type in triplicate.

\subsection{PAH sorption by sediments and effect of Superdispersant-25}

The effect of SD25 concentration on PAH sorption by sediments was evaluated in two stages as described in section $2.5 .12 \mathrm{ml}$ solutions containing $0.40 \mathrm{mg} \mathrm{PHE}^{-1}$ or $3.85 \mathrm{mg} \mathrm{NAP} \mathrm{l}^{-1}$ and SD25 at $0,10,20,30,100,200,300 \mathrm{mg}^{-1}$ in artificial seawater were prepared and added to $15 \mathrm{ml}$ glass centrifuge tubes lined with Teflon-lined caps. Samples were incubated and centrifuged as described in section 2.5. PAH concentration in seawater was determined by UVvis spectroscopy using a Lambda 25 UV/VIS Spectrometer (PerkinElmer). UV-vis spectra were measured with a $10 \mathrm{~mm}$ path-length quartz cuvette over the range $200-400 \mathrm{~nm}$. PHE and NAP concentrations were calculated from absorbances at 251 and $275 \mathrm{~nm}$, respectively. 5point calibration curves were prepared for each PAH and blanks with seawater only were ran after every 5 samples. Absorbances of blanks and solutions of SD25 in seawater and sediment were subtracted from measured values.

\subsection{Chemicals}

PHE (99\%), NAP (99\%), pristane (99\%) and dichloromethane (HPLC grade) were acquired from Sigma Aldrich (United Kingdom). Superdispersant-25 was acquired from Oil Technics (United Kingdom).

\subsection{Calculations and statistical modelling}

$K_{\mathrm{D}}$ can be envisaged as being composed of two terms to evaluate the contributions of surfactants to the sorption of PAHs to sediments (Lu and Zhu 2012):

$$
K_{D}=\frac{C_{s e d}}{C_{s w}}=K_{O C} f_{O C}+K_{s f} Q_{s f} \quad \text { Eq. } 2
$$

where $C_{\text {sed }}$ is the PAH concentration in sediment $\left(\mathrm{mg} \mathrm{g}^{-1}\right), C_{\mathrm{sw}}$ is the PAH concentration in seawater $\left(\mathrm{mg} \mathrm{l}^{-1}\right), K_{\mathrm{oc}}$ is the OC-normalised PAH distribution coefficient $\left(\mathrm{ml} \mathrm{g}^{-1}\right)$, calculated as 
$2180.35 K_{\text {ow }}$ (Octanol-water coefficient) (Seth et al. 1999), $f_{\text {oc }}$ is the OC fraction of the sediment, $K_{\mathrm{sf}}$ is the surfactant-normalised PAH distribution coefficient $\left(\mathrm{ml} \mathrm{g}^{-1}\right)$, defined here as $K_{\mathrm{SD} 25}$ (for $\mathrm{SD} 25)$ and $Q_{\mathrm{sf}}$ is the sediment-adsorbed surfactant concentration $\left(\mathrm{mg} \mathrm{g}^{-1}\right)$, defined here as $Q_{\mathrm{SD} 25}$ and including all components of the SD25 formulation. Analyte concentrations in sediment were calculated by subtracting the concentrations measured in in artificial seawater from initial concentrations added. For calculating of $K_{\mathrm{D}}$ values when no analyte was detected in the aqueous phase, a value of $0.001 \mathrm{mg}^{-1}$ was used as the concentration in seawater.

Response of sorption variables to SD25 concentration were modelled using locally weighed regressions due to the non-linearity of the data, where sorption variables were the response variable and SD25 concentration in either water or sediment was the explanatory variable, subset by PAH, sediment type and experimental stage (adsorption: first inoculation; desorption: replacement of supernatant with clean seawater). Briefly, the model fits a polynomial surface determined by PAH solubility. $Q_{\mathrm{SD} 25}$ values were estimated from locally weighed regressions from experiments described in Section 2.5. All statistical analysis was undertaken using $\mathrm{R}(\mathrm{R}$ Development Core Team 2017) and the library ggplot2 was used for locally weighted regression analysis (Wickham and Chang 2009).

\section{Results}

\subsection{Sediment characterisation and Superdispersant-25 critical micelle concentration}

FSC, SB and YE sediments were classified as silty loam, medium and fine sands, respectively. Details of particle size distribution and carbon content of the sediments analysed can be found in Table 1. The critical micelle concentration of Superdispersant-25 in artificial seawater $(\mathrm{T}=$ $20^{\circ} \mathrm{C}, \mathrm{S}=34$ ) was $5.8 \mathrm{mg} \mathrm{l}^{-1}$ (Fig. 2).

\subsection{Effect of Superdispersant-25 concentration on PAH solubility in seawater}

Solubility of PHE in artificial seawater linearly increased from $0.57 \pm 0.20$ to $4.44 \pm 1.32 \mathrm{mg}$ $\mathrm{l}^{-1}$ from 0 to $250 \mathrm{mg} \mathrm{SD} 25 \mathrm{l}^{-1}$ and decreased to $2.07 \pm 1.66 \mathrm{mg} \mathrm{l}^{-1}$ at $1000 \mathrm{mg} \mathrm{SD} 25 \mathrm{l}^{-1}$. Solubility 
of NAP in artificial seawater remained constant from 0 to $1000 \mathrm{mg} \mathrm{SD} 25 \mathrm{l}^{-1}(10.00 \pm 1.89$ and 272 $11.18 \pm 0.91 \mathrm{mg} \mathrm{l}^{-1}$, respectively, Fig. 3).

\subsection{Dispersant sorption onto sediments}

SD25 uptake by sediments differed across sediment type and [SD25]sw,0 range (Fig. 4). At [SD25] $]_{\mathrm{Sw}, 0}<175 \mathrm{mg} \mathrm{l}^{-1}$ all sediments took up all SD25 from solution and no evidence for desorption back into solution was detected in the desorption stage. In FSC sediment, uptake of all SD25 was observed across the range of $[\mathrm{SD} 25]_{\mathrm{sw}, 0}$ and no desorption was detected at any

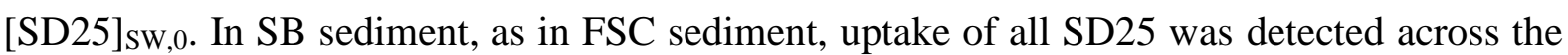
$[\mathrm{SD} 25]_{\mathrm{Sw}, 0}$ range tested. However, SD25 desorption was apparent at [SD25]sw,0>250 mg SD $\mathrm{l}^{-1}$. At [SD25] $]_{\mathrm{Sw}, 0}>175 \mathrm{mg} \mathrm{SD} 25 \mathrm{l}^{-1}$, YE sediment uptake of SD25 plateaued at $\sim 1.5 \mathrm{mg} \mathrm{g}^{-1}$, and desorption could not be inferred also due to high variability of [PHE].

\subsection{Effect of Superdispersant-25 on PAH uptake by sediments}

$K_{\mathrm{D}}$ values of NAP and PHE as a function of $Q_{\mathrm{SD} 25}$ to the sediments investigated varied with sediment type and experimental stage (adsorption or desorption) (Fig. 5). During the adsorption stage, SD25 application increased $K_{\mathrm{D}}$ values in YE and SB sediments but not in FSC sediment. As $Q_{\mathrm{SD} 25}$ increased, $K_{\mathrm{D}}$ values of both PAHs to $\mathrm{SB}$ and $\mathrm{YE}$ sediments increased. Desorption stage $K_{\mathrm{D}}$ values of both PAHs decreased relative to the adsorption stage. Desorption stage $K_{\mathrm{D}}$ values decreased with $Q_{\mathrm{SD} 25}$ in FSC sediments and increased in other sediment types, except for NAP in YE sediment, where no effect of $Q_{\mathrm{SD} 25}$ was apparent. The adsorption of PAHs to sediment-adsorbed SD25 was evaluated by comparing $K_{\mathrm{SD} 25}$ to $Q_{\mathrm{SD} 25}$ (Fig. 6). Overall, no clear patterns emerged for $K_{\mathrm{SD} 25}$ as a function of $Q_{\mathrm{SD} 25}$ during either the adsorption or desorption stages.

\section{Discussion}

\section{$270 \quad 4.1 \quad$ Key findings}

271 SD25 had contrasting effects on the water-solubility of PHE and NAP. PHE water-solubility was increased from SD25 concentration as low as $10 \mathrm{mg} \mathrm{l}^{-1}$ but NAP water-solubility was not 
affected by SD25, even at $1000 \mathrm{mg} \mathrm{l}^{-1}$. Sorption of SD25 by sediments varied by sediment type. FSC sediment took up all SD25 in solution across the [SD25] $]_{\mathrm{Sw}, 0}$ range tested and no desorption of SD25 was detected. In contrast, in SB and YE sediments SD25 desorption was apparent in experiments with [SD25] $]_{\mathrm{sw} 0}>250 \mathrm{mg} \mathrm{l}^{-1}$. Sorption dynamics of PAHs varied by $\mathrm{PAH}$, sediment type and $Q_{\mathrm{SD} 25}$. $Q_{\mathrm{SD} 25}$ increased $K_{\mathrm{D}}$ values of both PAHs in SB and YE sediments but did not have a clear effect on the adsorption of either PAH in FSC sediments. Desorption stage $K_{\mathrm{D}}$ values generally decreased with respect to the adsorption stage. There was no clear trend of PAH sorption to sediment-adsorbed dispersant as a function of $Q_{\mathrm{SD} 25}$.

\subsection{Effect of dispersant on PAH solubility in seawater}

283 SD25 application increased the water-solubility of PHE but not of NAP. PHE water-solubility could be increased up to seven-fold with dispersant application at $250 \mathrm{mg} \mathrm{l}^{-1}$ (Fig. 3). However, at SD25 concentration above $250 \mathrm{mg} \mathrm{l}^{-1}$, PHE solubility was reduced implying that SD25 may have an optimal concentration to mobilise target pollutants. SD25 application, even at SD25 concentration $<30 \mathrm{mg}^{-1}$, resulted in increased PHE solubility indicating that PAHs such as PHE can be readily dissolved and dispersed in the water column. Increasing the solubility of PAHs in the water column by dispersant facilitates their dilution and dispersion in the marine environment (Fingas 2002) which can aid in long-term removal. Hydrocarbons have been shown to photodegrade more rapidly when chemically dispersed with Corexit 9500A than in its absence (Zhao et al. 2016). Chemical dispersion may negatively impact or have no effect on hydrocarbon biodegradation in the water column by modifying the microbial community composition and selecting for potential dispersant-degrading bacteria Colwellia and not Marinobacter, a natural hydrocarbon degrader (Kleindienst et al. 2015). The overall benefits of dispersant to the marine environment remain debated although it can be beneficial given specific circumstances (Prince 2015).

[SD25 $]_{\mathrm{Sw}, 0}$ up to $1000 \mathrm{mg} \mathrm{l}^{-1}$ did not enhance NAP solubility $\left(\sim 11 \mathrm{mg} \mathrm{l}^{-1}\right)$ although there have been reports of higher water-solubility of NAP in seawater without surfactant addition (23.1 $\mathrm{mg} \mathrm{l}^{-1}$ at $25^{\circ} \mathrm{C}$ (Adelman 1977) and $28 \mathrm{mg} \mathrm{l}^{-1}$ at $20^{\circ} \mathrm{C}$ (Zhao et al. 2015)). Previous work using SD25 has shown that SD25 has limited effect on NAP mobility into sediments (Perez Calderon et al. 2018b, c, a). In contrast, investigations into NAP water-solubility have shown that Corexit 9500A can linearly increase its solubility in seawater. Zhao et al. (2015) reported that $200 \mathrm{mg}$ 
Corexit 9500 $\mathrm{A}^{-1}$ increased NAP solubility in seawater from 28 to $36 \mathrm{mg} \mathrm{l}^{-1}$. These apparent contradictions illustrate that different commercial dispersants and seawater types may solubilise specific hydrocarbons to different extents. Therefore, conclusions drawn from work using one oil-dispersant-seawater system may not be transferable to another system with a different dispersant or seawater. This is important given that a large body of literature has been produced following the $\mathrm{DwH}$ oil spill using Corexit dispersants which may only be relevant in the context of the Macondo oil-Corexit dispersant combination. Therefore, further research is required into how different dispersants affect oil-water interactions.

\subsection{Superdispersant-25 sorption by sediments}

All SD25 across the concentration range tested was adsorbed onto FSC sediment and did not desorb following water replacement (Fig. 4). This finding highlights the strong uptake capacity of SD25 by fine deep-sea sediments. Subsea application of dispersant, as witnessed during the $D w H$ oil spill resulted in significant amounts of dispersant ending up on the seabed (White et al. 2014). The proposed pathways of dispersant deposition on the Gulf of Mexico seabed are thought to be surface sorption and settling of dispersant-suspended particle aggregates (Gong et al. 2014b; White et al. 2014). Sorption of non-polar hydrophobic pollutants to sediments is dependent on organic matter content and if it is above $0.01 \%$, it may take up the majority of the pollutant as opposed to the mineral component of the sediment (Pignatello 1998). In this experiment, this was verified for SD25 as maximum uptake was observed by high OCcontaining sediments (FSC and $\mathrm{SB}$ ) as opposed to low OC-containing sediment (YE). Desorption of SD25 was detected in SB but not in FSC sediment potentially due to the difference in percentage of fines between sediment types (Fig. 4). Dispersant has been found to persist in deep-sea sediments and corals for over four years following the $D w H$ oil spill and that environmental conditions in deposition sites influenced its residence time (White et al. 2014). Results here suggest that responders should consider sediment characteristics as part of the decision-making process for dispersant application in the marine environment due to the capacity of dispersant to adsorb to marine sediments, particularly when sediments are fine or OC-rich. For example, in a hypothetic offshore well blowout scenario, SD25 application near fine sediments, such as FCS sediments, may enhance uptake of SD25, oil droplets and dissolved hydrocarbons more readily than other sediments. This can yield more negative effects for benthic ecosystems than application at surface waters where oil and dispersant are less 
likely to come into contact with the seabed. On the other hand, if the seabed is sandy, application of SD25 near the seabed is less likely to result in adsorption of hydrocarbons although it may enhance entrainment via advective pore-water transport (Perez Calderon et al. 2018c). This is particularly important if protected species such as sand eels are near the target site for SD25 application as they are sensitive to oil (Heath and Bailey 1994).

\subsection{Effect of dispersant on PAH uptake by sediments}

$343 K_{\mathrm{D}}$ values of NAP and PHE varied with sediment type, $Q_{\mathrm{SD} 25}$ and experimental stage to varying 344 extents (Figs 5,Fig. 6). In FSC sediments, $Q_{\mathrm{SD} 25}$ did not affect $K_{\mathrm{D}}$ values of either PAH in the 345 adsorption stage which is likely due to the high proportion of fines $(70.8 \%)$ and OC (1.67\%). 346 In contrast, in sandy sediments with a lower proportion of fines such as SB and YE sediments, 347 uptake increased with $Q_{\mathrm{SD} 25}$ suggesting that surfactant sorption may create new adsorption sites 348 in coarser sediments as previously reported for PHE in sandy loam and loamy sand using 349 Corexit 9500A (Gong et al. 2014b). Corexit 9500A in solution (18 $\left.\mathrm{mg}^{-1}\right)$ has been shown to 350 have limited effects on NAP sorption to sandy loam and loamy sand, increasing in NAP uptake 351 by sediment of $2.9 \%$ and $3.3 \%$, respectively (Zhao et al. 2015). Here, the highest uptake of NAP was measured in YE sediments at $\sim 0.8 \mathrm{mg} \mathrm{SD}^{2} \mathrm{~g}^{-1}$ (Fig. 5) although no effect of SD25 on naphthalene solubility was apparent (Fig. 4). However, no NAP was detected in the aqueous phase in these samples and the default value of $0.001 \mathrm{mg} \mathrm{l}^{-1}$ was assigned which may have skewed the $K_{\mathrm{D}}$ values of NAP in these samples. Desorption-phase $K_{\mathrm{D}}$ values across sediments for both NAP and PHE decreased indicating that adsorption of both NAP and PHE in these sediments was partially reversible. Increasing $Q_{\mathrm{SD} 25}$ reduced desorption stage $K_{\mathrm{D}}$ values of NAP in FSC sediments suggesting that SD25 uptake increased the partitioning of NAP to the aqueous phase. In contrast, desorption stage $K_{\mathrm{D}}$ values of NAP in SB or YE did not vary with $Q_{\text {SD25 }}$ suggesting that sediment-adsorbed SD25 does not retain NAP in sandy sediments with seawater exchange.

The effect of $Q_{\mathrm{SD} 25}$ on the desorption of PHE was similar to that in the adsorption stage in SB and YE sediments suggesting that PHE remains more strongly adsorbed to marine sediments with increasing $Q_{\mathrm{SD} 25}$ than NAP. Desorption stage $K_{\mathrm{D}}$ values of PHE in YE sediments were approximately one order of magnitude higher than those of NAP (Fig. 5) suggesting that, even in the absence of fines, PHE may remain strongly adsorbed onto sandy sediments. Strong 
adsorption of PAHs to silty loams following continuous desorption experiments has been recently reported (Duan et al. 2018). The authors also reported that addition of Corexit 9500A and SPC 100 increased desorption of PAHs and to a lesser extent that of alkanes. Similarly, Gong et al. (2014) reported increased hysteresis of PHE in sandy loam and loamy sand at increasing Corexit 9500A, suggesting that SD25 may be less effective at desorbing NAP and PHE from marine sediments although it does increase their solubility in seawater. The contribution of $Q_{\mathrm{SD} 25}$ to $K_{\mathrm{SD} 25}$ values of either $\mathrm{PAH}$ in this experiment was unclear. Previous research showed increased adsorption of organic pollutants to sediment-bound dodecylpyridinium bromide, even in humic acid with $\sim 50 \%$ OC where OC would be expected to adsorb the majority of the pollutant ( $\mathrm{Lu}$ and $\mathrm{Zhu} 2012$ ). This difference may arise from the use of a different dispersant formulation (SD25).

Disparity in response to SD25 application has been observed in hydrocarbon pore-water transport experiments where NAP and PHE were mixed with hydrocarbons from other fractions (BTEX, aliphatics and other PAHs) (Perez Calderon et al. 2018b, c, a). The effect of SD25 on NAP mobility in sediments in these experiments was limited, suggesting a similar "behaviour" to that observed here. In contrast, PHE mobility in sediments increased with SD25 application in these experiments. The solubilising effect of SD25 was masked by the high water-solubility of NAP but was apparent for PHE, even when in the same system. Other hydrocarbons were found to not be affected by SD25-application (e.g. BTEX) which are also highly water-soluble, suggesting this is the key property that governs the extent to which SD25 affects hydrocarbons in these systems.

388 The findings here show the effects of SD25 on PAH-sediment-seawater dynamics in three 389 sediments from the North Sea and FSC. Adsorption of PAHs to sediments was facilitated by 390 SD25 application. The driving mechanism appeared to be the solubilising effect of SD25 on 391 PAHs as $Q_{\mathrm{SD} 25}$ did not appear to drive PAH adsorption onto FSC sediments, suggesting that 392 SD25 application in a subsea blowout in the FSC may not increase sorption of PAHs but may 393 result in SD25 adsorption to sediment, where dispersants can persist for years (White et al. 394 2014) and affect microbial community composition (Ferguson et al. 2017; Perez Calderon et al. 2018b). In contrast, increased uptake of PAHs by SB and YE sediments with increasing $Q_{\mathrm{SD} 25}$ suggest that less sorptive sediments (i.e. with lower OC and fines percentages) may increase their uptake of PAHs through sediment-adsorbed SD25. It is important to note that sediments here were sterilised and artificial seawater used and such bacterial activity in the sediments was reduced. Consequently, the role of biodegradation, biosurfactant production and 
transparent exopolymeric particle production has not been considered here. These processes may have a marked effect on sorption dynamics. For example, biodegradation reduces surfactant concentration in media through microbial metabolism (Brakstad et al. 2018), which may limit hydrocarbon uptake by sediments. Biosurfactant production increases PAH bioavailability and can enhance biodegradation (Lu et al. 2011), which can decrease their concentration in sediments. Finally, transparent exopolymeric particles (colloidal organic carbon structures containing acidic polysaccharides) play a key role in adsorbing particulates in the wider ocean (Rochelle-Newall et al. 2010). They can act as binding sites for dispersant and remove surfactants and PAHs from solution as suggested in the MOSSFA hypothesis, whereby marine snow acted as a pathway for deposition of hydrocarbons and dispersant on the deep seabed after $D w H$ (Passow 2016). The role of these biological processes cannot be ignored in a real oil spill. However, the focus here was on the physical interactions between PAHs, dispersants and sediments. Further research is required to evaluate the physicochemical processes investigated here in conjunction with biological processes how the sorption dynamics of other, larger PAHs are affected by dispersant application.

\section{Conclusions}

The present study evaluated the sorption dynamics of PHE and NAP in three marine sedimentsseawater systems and the effect of SD25 concentration on this process. The main findings of the study were:

1. Dispersant increased the solubility of PHE in seawater up to seven-fold but had no effect on the solubility of NAP. This contrasts with previous work, where NAP solubility was enhanced with Corexit 9500A, suggesting that different dispersant formulations can selectively solubilise specific PAHs in seawater. Dispersant choice should be considered by responders to account for selective solubilisation of toxic chemicals such as PAHs and the potential knock-on effects this choice may have on the wider marine environment, e.g. the seabed as discussed here.

2. FSC and SB sediments adsorbed all SD25 across the concentration range tested (up to $\sim 5 \mathrm{mg} \mathrm{g}^{-1}$ ) but no desorption could be measured in FSC sediments suggesting SD25 can remain strongly bound to fine sediments. In YE sediments, sorption of SD25 was more limited (up to $\sim 1.5 \mathrm{mg} \mathrm{g}^{-1}$ ) and desorption of SD25 was highly variable. 

455

3. Sorption dynamics of both PAHs were affected by sediment type and $Q_{\mathrm{SD} 25}$ to different extents. $K_{\mathrm{D}}$ values decreased in the desorption stage compared to the adsorption stage for both PAHs. $Q_{\mathrm{SD} 25}$ increased adsorption of both PAHs in SB and YE but not FSC sediments. The finding suggests that SD25 increased sediment uptake of PAHs but did not retain them strongly adsorbed to the sediment following water replacement.

4. $Q_{\mathrm{SD} 25}$ did not have a clear effect on $K_{\mathrm{SD} 25}$ values of either PAH, suggesting that sediment-adsorbed SD25 increases the adsorption of these PAHs to sediment but not onto sediment-adsorbed SD25.

439 The results provide evidence of SD25 influence on the sorption dynamics of PAHs in marine sediments, which varies by sediment type and PAH. The results highlight the importance of considering the relationship between SD25 and sorption dynamics on the fate of PAHs in marine sediments following an oil spill. Further research into the sorption dynamics of PAHs across commercial dispersants, sediment types, within hydrocarbon mixtures and biotic interactions is required to evaluate the potential effects of dispersant on oil-sediment interactions.

Acknowledgements: LJP was funded through MarCRF funds for a $\mathrm{PhD}$ project designed by UW, JA and AG and awarded to LJP. The authors acknowledge the assistance of Mike Mcgibbon in analysing carbon content, the crews of the MRV Scotia and MRV Temora for sample collection. Dr. Hedda Weitz and Prof. Graeme Patton are thanked for facilitating access to laboratory space and equipment.

\section{References}

454 Adelman IR (1977) Effects of Pollutants on Aquatic Organisms. J Environ Qual 6:474. doi: $10.2134 /$ jeq1977.00472425000600040037x

Ashworth J, Keyes D, Kirk R, Lessard R (2001) Standard procedure in the hydrometer method for particle size analysis. Commun Soil Sci Plant Anal 32:633-642. doi: 10.1081/CSS-100103897

Baes CF, Sharp RD (1983) A proposal for estimation of soil leaching and leaching constants for use in assessment models. J Environ Qual 12:17. doi: 10.2134/jeq1983.00472425001200010003x

Bandara UC, Yapa PD, Xie H (2011) Fate and transport of oil in sediment laden marine waters. J Hydroenvironment Res 5:145-156. doi: 10.1016/j.jher.2011.03.002 
Beyer J, Trannum HC, Bakke T, et al (2016) Environmental effects of the Deepwater Horizon oil spill: A review. Mar Pollut Bull 110:28-51. doi: 10.1016/j.marpolbul.2016.06.027

Blott SJ, Pye K (2001) GRADISTAT: a grain size distribution and statistics package for the analysis of unconsolidated sediments. Earth Surf Process Landforms 26:1237-1248. doi: 10.1002/esp.261

Brakstad OG, Størseth TR, Brunsvik A, et al (2018) Biodegradation of oil spill dispersant surfactants in cold seawater. Chemosphere 204:290-293. doi: 10.1016/j.chemosphere.2018.04.051

Chanton J, Zhao T, Rosenheim BE, et al (2015) Using natural abundance radiocarbon to trace the flux of petrocarbon to the seafloor following the Deepwater Horizon oil spill. Environ Sci Technol 49:847-854. doi: 10.1021/es5046524

Dixon T (2015) Annual survey of reported discharges and releases attributed to vessels and offshore oil and gas installations operating in the united kingdom's exclusive economic zone (UK EEZ) 2014. Advisory Committee on Protection of the Sea. Cambridge, UK

Duan J, Liu W, Zhao X, et al (2018) Study of residual oil in Bay Jimmy sediment 5 years after the Deepwater Horizon oil spill: Persistence of sediment retained oil hydrocarbons and effect of dispersants on desorption. Sci Total Environ 618:1244-1253. doi: 10.1016/j.scitotenv.2017.09.234

Ferguson RMW, Gontikaki E, Anderson JA, Witte U (2017) The variable influence of dispersant on degradation of oil hydrocarbons in subarctic deep-sea sediments at low temperatures $\left(0-5^{\circ} \mathrm{C}\right)$. Sci Rep 7:2253. doi: 10.1038/s41598-017-02475-9

Fingas MF (2002) A review of literature related to oil spill dispersants especially relevant to Alaska. Environmental Technology Centre. Anchorage, USA

Gong Y, Zhao X, Cai Z, et al (2014a) A review of oil, dispersed oil and sediment interactions in the aquatic environment: Influence on the fate, transport and remediation of oil spills. Mar Pollut Bull 79:16-33. doi: 10.1016/j.marpolbul.2013.12.024

Gong Y, Zhao X, O'Reilly SE, et al (2014b) Effects of oil dispersant and oil on sorption and desorption of phenanthrene with Gulf Coast marine sediments. Environ Pollut 185:240-249. doi: 10.1016/j.envpol.2013.10.031

Hayworth JS, Prabakhar Clement T, John GF, Yin F (2015) Fate of Deepwater Horizon oil in Alabama's beach system: Understanding physical evolution processes based on observational data. Mar Pollut Bull 90:95-105. doi: 10.1016/j.marpolbul.2014.11.016

Heath MR, Bailey MC (1994) The impact of the Braer oil spill on sandeel availability to seabirds around Shetland. The effects of the oil spill on the growh and development of early life history stages. Marine Laboratory. Aberdeen, UK

John JA, Draper NR (1980) An alternative family of transformations. Appl Stat 29:190-197. doi: $10.2307 / 2986305$

Kleindienst S, Seidel M, Ziervogel K, et al (2015) Chemical dispersants can suppress the activity of natural oil-degrading microorganisms. Proc Natl Acad Sci 112:14900-14905. doi: 


\subsection{3/pnas. 1507380112}

Lu L, Zhu L (2012) Effect of soil components on the surfactant-enhanced soil sorption of PAHs. J Soils Sediments 12:161-168. doi: 10.1007/s11368-011-0432-6

Lu XY, Zhang T, Fang HHP (2011) Bacteria-mediated PAH degradation in soil and sediment. Appl Microbiol Biotechnol 89:1357-1371. doi: 10.1007/s00253-010-3072-7

Marini M, Frapiccini E (2013) Persistence of polycyclic aromatic hydrocarbons in sediments in the deeper area of the Northern Adriatic Sea (Mediterranean Sea). Chemosphere 90:1839-1846. doi: 10.1016/j.chemosphere.2012.09.080

Mason OU, Scott NM, Gonzalez A, et al (2014) Metagenomics reveals sediment microbial community response to Deepwater Horizon oil spill. ISME J 8:1464-1475. doi: 10.1038/ismej.2013.254

Matthies M (2011) Handbook of chemical mass transport in the environment, Toxicological \& Environmental Chemistry, 93:6, 1274-1275, doi: 10.1080/02772248.2011.585777Mearns AJ, Reish DJ, Oshida PS, Ginn T (2010) Effects of pollution on marine organisms. Water Environ Res 82:2001-2046. doi: 10.2175/106143010X12756668802175

Office of Solid Waste (2008) Polycyclic Aromatic Hydrocarbons (PAHs). U.S. Environmental Protection Agency, Washington, DC, USA

Passow U (2016) Formation of rapidly-sinking, oil-associated marine snow. Deep Sea Res Part II Top Stud Oceanogr 129:232-240. doi: 10.1016/j.dsr2.2014.10.001

Perez Calderon LJ, Potts LD, Cornulier T, et al (2018a) The effect of chemical dispersant concentration on hydrocarbon mobility through permeable North-East Scotland sands. Estuar Coast Shelf Sci 214:72-81. doi: 10.1016/j.ecss.2018.09.008

Perez Calderon LJ, Potts LD, Gontikaki E, et al (2018b) Bacterial community response in deep FaroeShetland Channel sediments following hydrocarbon entrainment with and without dispersant addition. Front Mar Sci 5:. doi: 10.3389/fmars.2018.00159

Perez Calderon LJ, Vossen K, Potts LD, et al (2018c) Advective pore-water transport of hydrocarbons in North East Scotland coastal sands. Environ Sci Pollut Res 25:28445-28459. doi: $10.1007 / \mathrm{s} 11356-018-2815-3$

Piatt JJ, Backhus DA, Capel PD, Eisenreich SJ (1996) Temperature-dependent sorption of naphthalene, phenanthrene, and pyrene to low organic carbon aquifer sediments. Environ Sci Technol 30:751760. doi: 10.1021/es9406288

Pietroski JP, White JR, DeLaune RD (2015) Effects of dispersant used for oil spill remediation on nitrogen cycling in Louisiana coastal salt marsh soil. Chemosphere 119:562-567. doi: 10.1016/j.chemosphere.2014.07.050

Pignatello JJ (1998) Soil organic matter as a nanoporous sorbent of organic pollutants. Adv Colloid Interface Sci 76-77:445-467. doi: 10.1016/S0001-8686(98)00055-4

Prince RC (2015) Oil spill dispersants: boon or bane? Environ Sci Technol 49:6376-6384. doi: 10.1021/acs.est.5b00961 
R Development Core Team (2017) R: A language and environment for Statistical computing. R Found. Stat. Comput.

Reed M, Johansen Ø, Brandvik PJ, et al (1999) Oil spill modeling towards the close of the 20th century: overview of the state of the art. Spill Sci Technol Bull 5:3-16. doi: 10.1016/S13532561(98)00029-2

Rochelle-Newall EJ, Mari X, Pringault O (2010) Sticking properties of transparent exopolymeric particles (TEP) during aging and biodegradation. J Plankton Res 32:1433-1442. doi: 10.1093/plankt/fbq060

Seth R, Mackay D, Muncke J (1999) Estimating the organic carbon partition coefficient and its variability for hydrophobic chemicals. Environ Sci Technol 33:2390-2394. doi: $10.1021 / \mathrm{es} 980893 \mathrm{j}$

Webster L, Russell M, Walsham P, et al (2016) Determination and Environmental Assessment of Hydrocarbons in Water Samples Following a Release of Oil from the Clair Platform. Scottish Mar Freshw Sci 7:1-28. doi: 10.7489/1878-1

White HK, Lyons SL, Harrison SJ, et al (2014) Long-Term Persistence of Dispersants following the Deepwater Horizon Oil Spill. Environ Sci Technol Lett 1:295-299. doi: 10.1021/ez500168r

Wickham H, Chang W (2009) ggplot2: elegant graphics for data analysis

Xing B, Pignatello JJ, Gigliotti B (1996) Competitive sorption between atrazine and other organic compounds in soils and model sorbents. Environ Sci Technol 30:2432-2440. doi: $10.1021 / \mathrm{es} 950350 \mathrm{z}$

Yamada M, Takada H, Toyoda K, et al (2003) Study on the fate of petroleum-derived polycyclic aromatic hydrocarbons (PAHs) and the effect of chemical dispersant using an enclosed ecosystem, mesocosm. Mar Pollut Bull 47:105-113. doi: 10.1016/S0025-326X(03)00102-4

Zhao X, Gong Y, O'Reilly SE, Zhao D (2015) Effects of oil dispersant on solubilization, sorption and desorption of polycyclic aromatic hydrocarbons in sediment-seawater systems. Mar Pollut Bull 92:160-169. doi: 10.1016/j.marpolbul.2014.12.042

Zhao X, Liu W, Fu J, et al (2016) Dispersion, sorption and photodegradation of petroleum hydrocarbons in dispersant-seawater-sediment systems. Mar Pollut Bull 109:526-538. doi: 10.1016/j.marpolbul.2016.04.064

\section{Tables}

Table 1. Carbon content (total (TC), organic (TOC) and inorganic (TIC)) and particle size distribution of sediments used in sorption experiments. Average percentages are expressed in terms of mass and errors refer to standard deviation $(n=3)$.

\begin{tabular}{lccccrr}
\hline Station & TC (\%) & TIC (\%) & TOC (\%) & Sand (\%) & \multicolumn{1}{c}{ Silt (\%) } & Clay (\%) \\
\hline FSC & $2.164 \pm 0.028$ & $0.490 \pm 0.009$ & $1.674 \pm 0.019$ & $29.3 \pm 4.2$ & $65.5 \pm 4.4$ & $5.3 \pm 2.4$ \\
SB & $1.014 \pm 0.027$ & $0.040 \pm 0.080$ & $0.977 \pm 0.103$ & $95.6 \pm 1.2$ & $3.7 \pm 1.0$ & $0.7 \pm 0.2$
\end{tabular}




\section{Figure captions}

Fig. 1. Sampling locations of sediments used in sorption experiments from the Faroe-Shetland Channel 572 (FSC, yellow pin), Ythan estuary (YE, red pin) and Stonehaven Bay (SB, green pin).

573 Fig. 2. Effect of Superdispersant-25 on artificial seawater surface tension. Circles and crosses represent 574 values below and above the change in slope. The solid and dashed lines represent models before and 575 after slope change. The solution for the intersection of the two equations is the CMC the critical micelle 576 concentration of Superdispersant-25 $\left(4.63 \mathrm{mg} \mathrm{l}^{-1}\right)$. Grey bands represent standard error of linear models. 577 Note SD25 concentration has been $\log (\mathrm{x}+1)$ transformed.

578 Fig. 3. Effect of initial Superdispersant- 25 concentration in seawater $\left([\mathrm{SD} 25]_{\mathrm{sw}, 0}\right)$ on PAH solubility in 579 artificial seawater $(S=34)$. Circles and crosses represent concentrations of naphthalene and 580 phenanthrene, respectively. Solid and dashed lines, and grey bands represent locally weighted smooth 581 regression predicted values and standard errors for naphthalene and phenanthrene, respectively.

582 Fig. 4. Superdispersant-25 uptake $\left(Q_{\mathrm{SD} 25}\right)$ onto sediments from the Faroe-Shetland Channel $(70.8 \%$ 583 fines), Stonehaven Bay (4.4\% fines) and Ythan Estuary ( $0 \%$ fines) as a function of initial 584 Superdispersant-25 concentration in seawater ([SD25] $]_{\mathrm{sw}, 0}$ ). Circles and crosses represent adsorption 585 and desorption steps, respectively. Solid and dashed lines, and grey bands represent locally weighted 586 smooth regression predicted values and standard errors for adsorption and desorption isotherms, 587 respectively.

588 Fig. 5. Effect of sediment Superdispersant-25 concentration $\left(Q_{\mathrm{SD} 25}\right)$ on the distribution coefficient $\left(K_{\mathrm{D}}\right)$ 589 of naphthalene and phenanthrene in sediments from the Faroe-Shetland Channel (70.8\% fines), 590 Stonehaven Bay (4.4\% fines) and Ythan Estuary (0\% fines). Circles and crosses represent adsorption 591 and desorption steps, respectively. Solid and dashed lines, and grey bands represent locally weighted 592 smooth regression predicted values and standard errors for adsorption and desorption isotherms, 593 respectively. Note the log-scale in the y-axis.

594 Fig. 6. Effect of sediment uptake of Superdispersant-25 $\left(Q_{\mathrm{SD} 25}\right)$ on the distribution coefficient $\left(K_{\mathrm{SD} 25}\right)$ 595 of naphthalene and phenanthrene to sediment-adsorbed Superdispersant-25 surfactants in sediments 596 from the Faroe-Shetland Channel (70.8\% fines), Stonehaven Bay (4.4\% fines) and Ythan Estuary (0\% 597 fines). Circles and crosses represent adsorption and desorption steps, respectively. Solid and dashed 598 lines, and grey bands represent locally weighted smooth regression predicted values and standard errors 599 for adsorption and desorption isotherms, respectively. Y-axis scaling is log-modulus transformed to 600 facilitate visualisation (John and Draper 1980). 
Faroe Islands

FSC

\section{Shetland Islands}

\section{United Kingdom}

400 km 


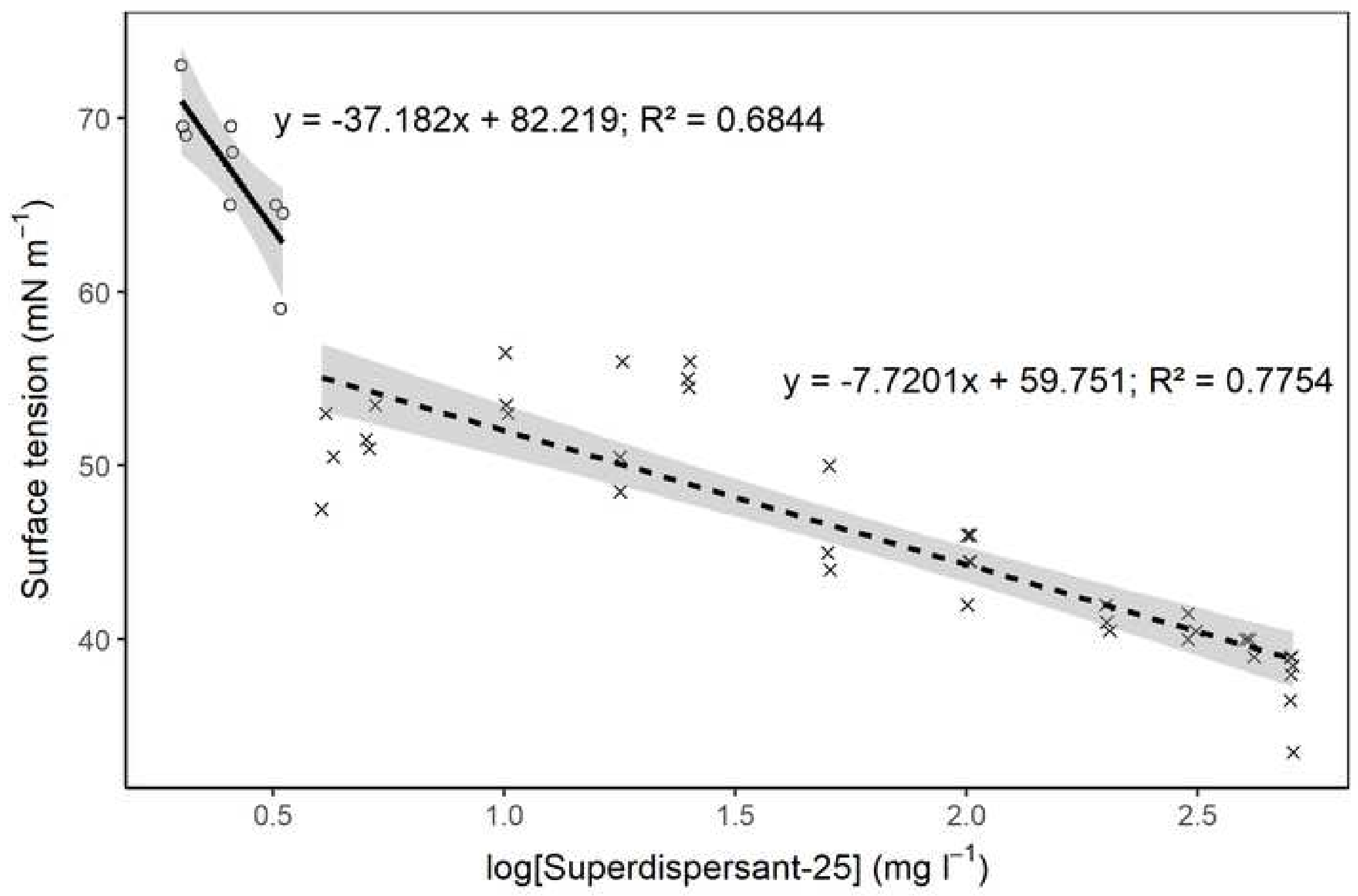




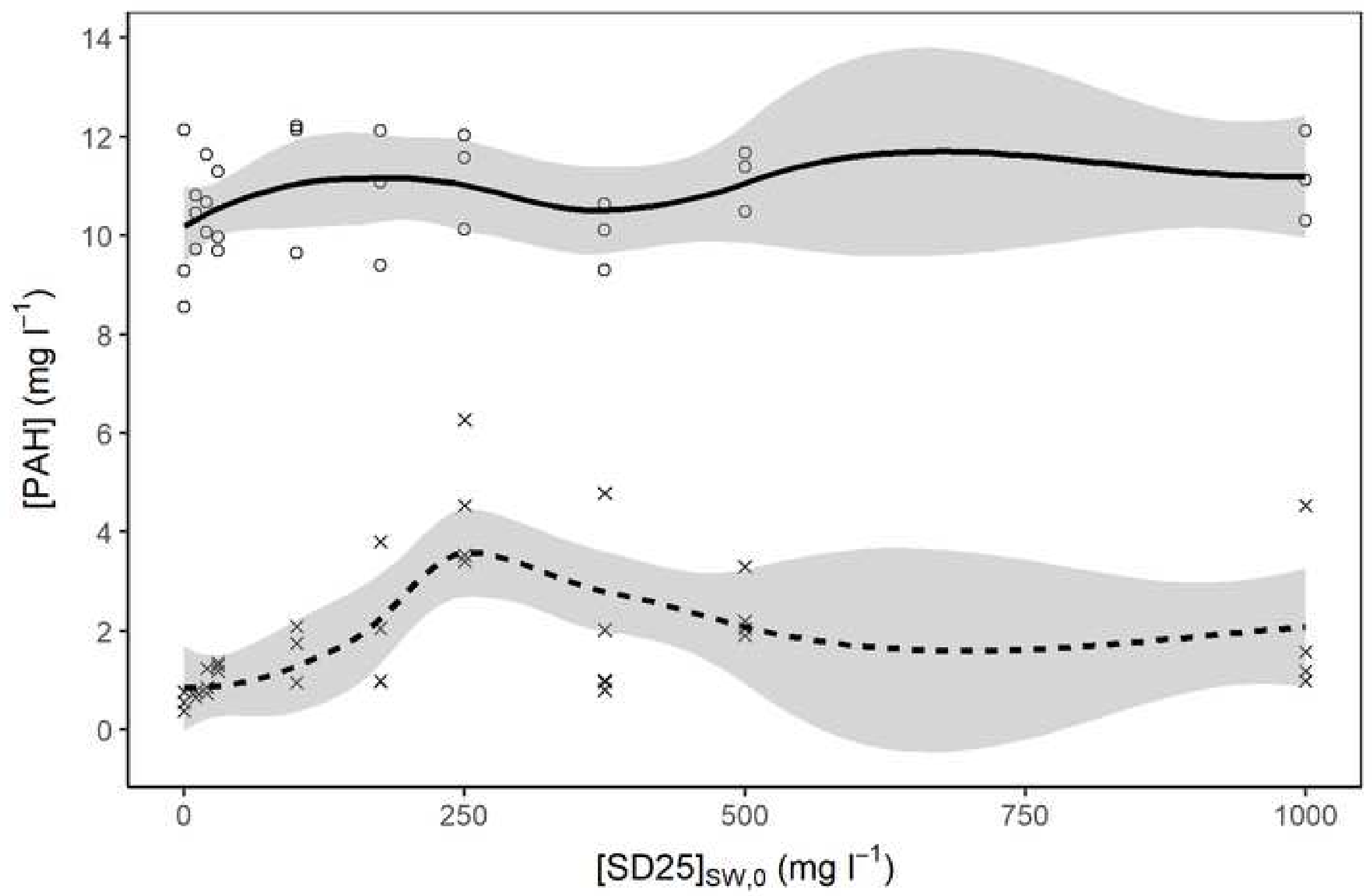




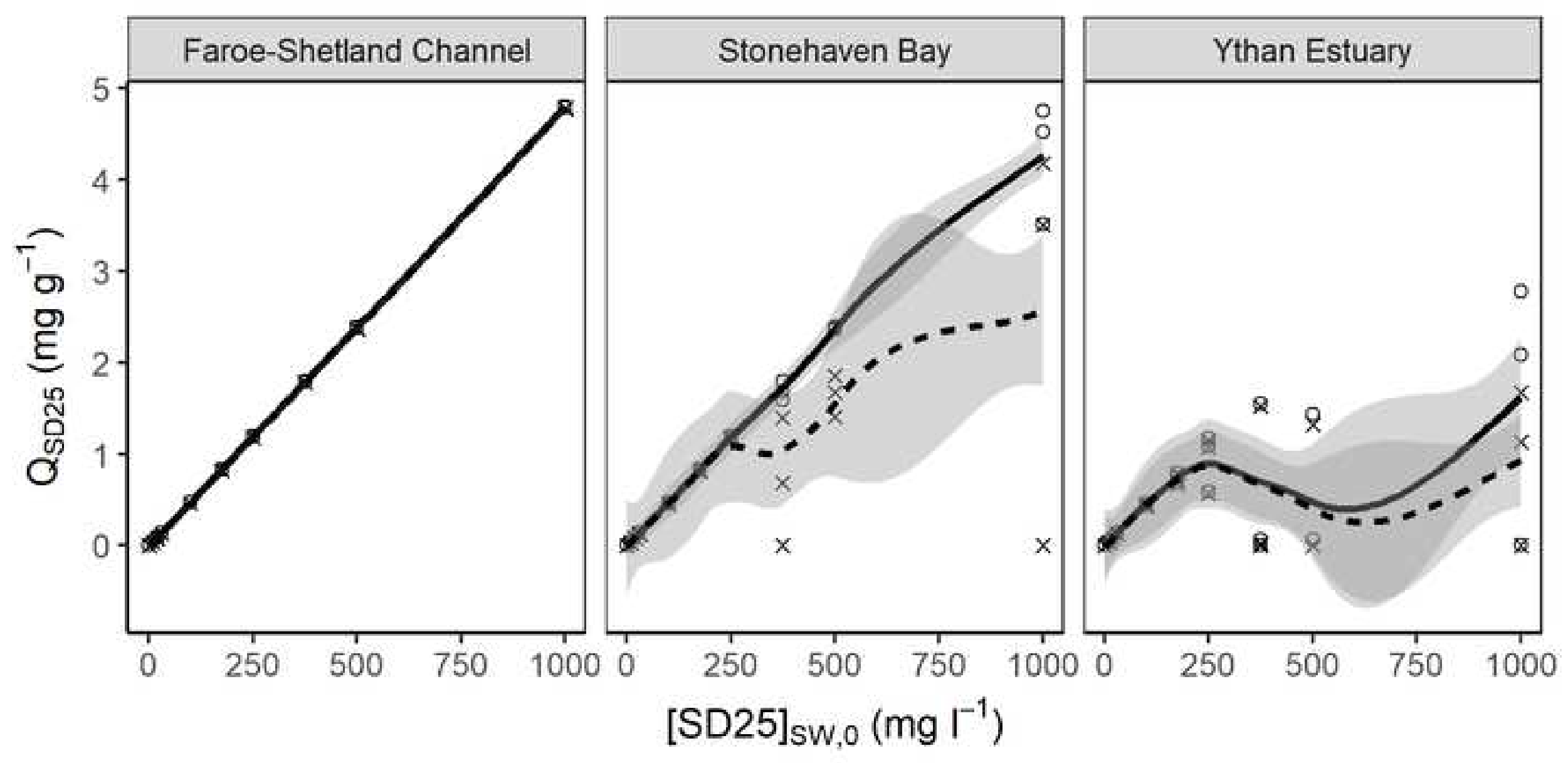



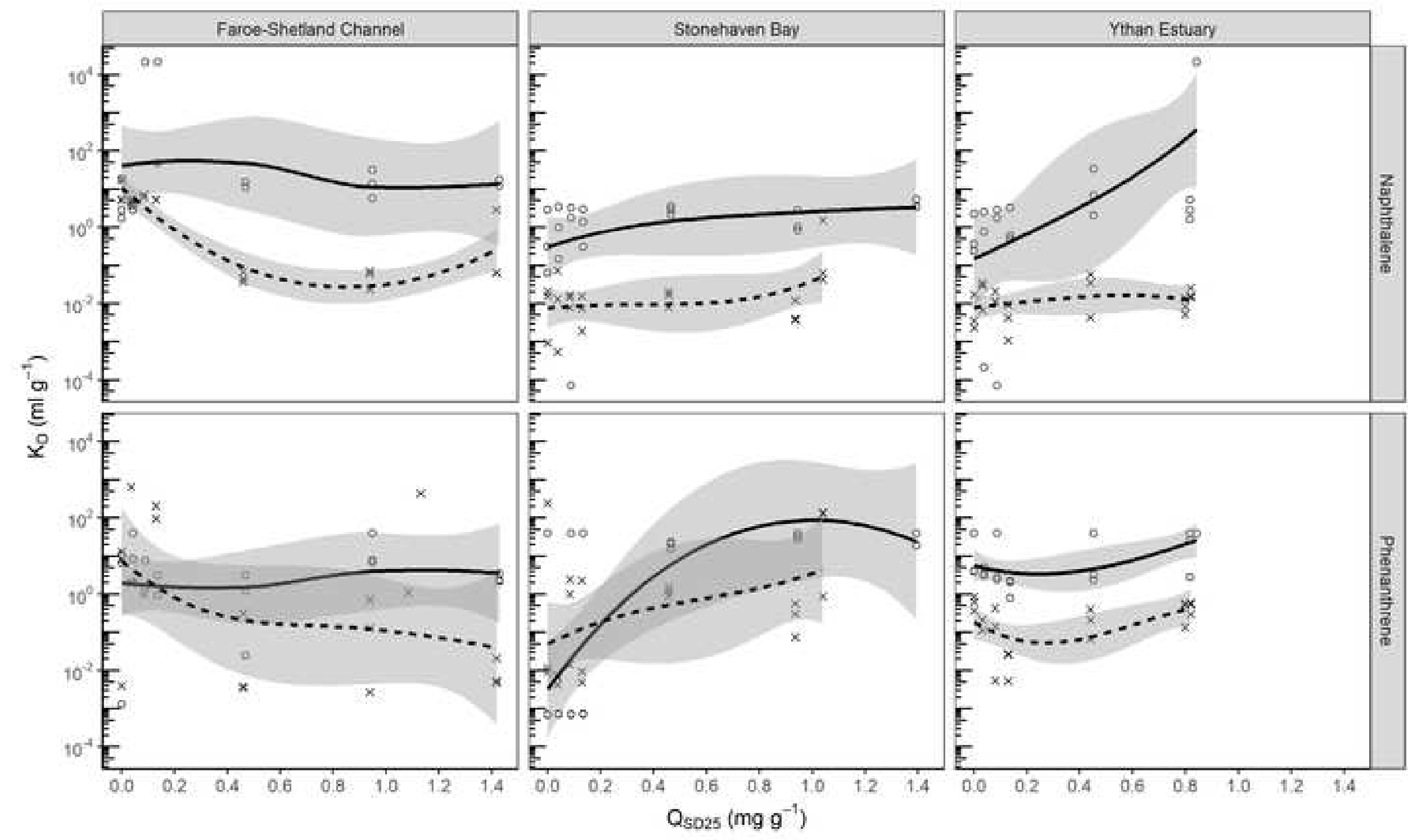

$\mathrm{Q}_{\mathrm{SD} 25}\left(\mathrm{mg} \mathrm{g}^{-1}\right)$ 

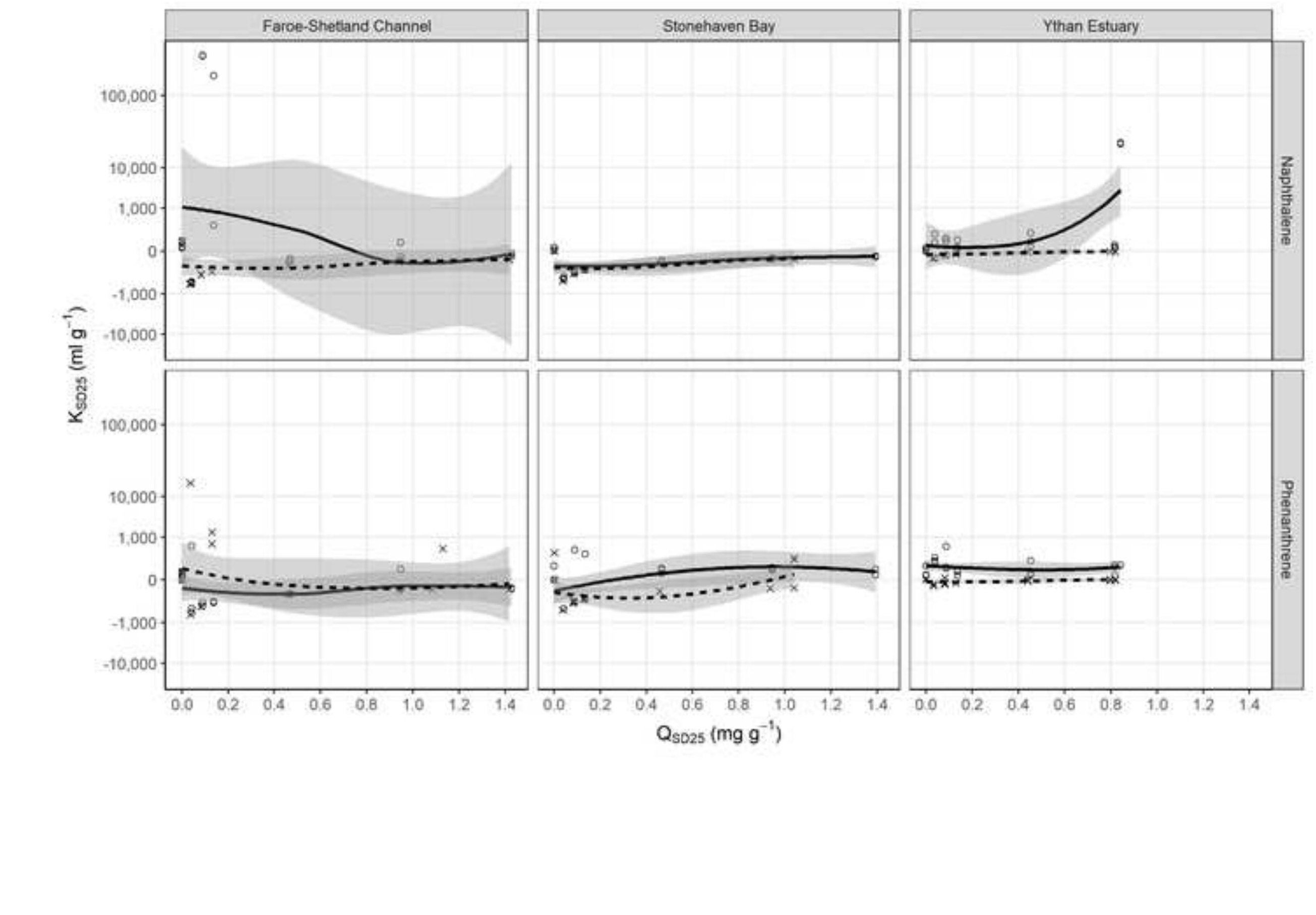

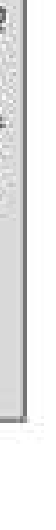


1 SEDIMENTS, SEC 2 • PHYSICAL AND BIOGEOCHEMICAL PROCESSES •

1

2

3

4

2 RESEARCH ARTICLE

3

4 Effects of Superdispersant-25 on the sorption dynamics of naphthalene and 5 phenanthrene in marine sediments

6

7 Luis J. Perez Calderon ${ }^{1,2,3}$ • Lloyd D. Potts ${ }^{1}$ • Alejandro Gallego ${ }^{3}$ • James A. Anderson ${ }^{2}$ • 8 Ursula Witte ${ }^{1}$

$10{ }^{1}$ Institute of Biological and Environmental Science, University of Aberdeen, Aberdeen, United 11 Kingdom

$12{ }^{2}$ Surface Chemistry and Catalysis Group, Materials and Chemical Engineering, Department of 13 Engineering, University of Aberdeen, Aberdeen, United Kingdom

14 Marine Scotland Science, Marine Laboratory Aberdeen, Aberdeen, United Kingdom

$17 \bowtie$ Luis J. Perez Calderon

18 lj.perezcalderon@gmail.com 


\section{Abstract}

21 Purpose: The present study evaluated the effects of Superdispersant-25 (SD25), a commercial

22 dispersant stockpiled in the United Kingdom for oil spill response, on the sorption dynamics

23 of two polyaromatic hydrocarbons, naphthalene (NAP) and phenanthrene (PHE), in sediment-

24 seawater systems using three sediments near hydrocarbon exploration areas in the Faroe-

25 Shetland Channel and North Sea.

26 Materials and methods: Batch experiments were conducted to evaluate the effects of SD25 on

27 the solubility (analysed by gas chromatography), distribution coefficients and desorption

28 hysteresis of NAP and PHE separately as well as SD25 in the three sediments (analysed by

29 UV-vis spectroscopy and surface tension measurements, respectively).

30 Results and discussion: The results revealed that SD25 readily adsorbed to all sediment types 31 but did not desorb from silty loam. SD25 application increased the solubility in seawater of 32 PHE but not of NAP. Adsorbed SD25 increased the distribution coefficients of both 33 polyaromatic hydrocarbons in sand but not silty loam and the solubilising effect of SD25 34 appeared to drive increased adsorption of PHE rather than sediment-adsorbed SD25 35 concentration.

36 Conclusions: The findings highlight the influence of SD25 application on the sorption 37 dynamics of NAP and PHE in marine sediments from areas near hydrocarbon exploration and 38 production regions. An understanding of these interactions may aid responders in the decision39 making process of dispersant application in the event of a spill as seabed characteristics affect 40 oil-dispersant-sediment interactions.

41 Keywords Dispersant $\bullet$ Naphthalene $\bullet$ Oil spill $\bullet$ PAHs $\bullet$ Phenanthrene $\bullet$ Sediment $\bullet$ Solubility 42 - Sorption 


\section{Introduction}

44 Hydrocarbon exploration and extraction in the United Kingdom continental shelf has been ongoing for approximately 40 years. In 2014 alone, a total of 30 oil spills (>2 t) have taken place in the United Kingdom Continental Shelf (Dixon 2015). More recently, the BP Clair spill resulted in the release of $95 \mathrm{t}$ of crude oil into the North Sea in 2016 (Webster et al. 2016). Oil releases to the marine environment are ecologically undesirable due to the persistence of oil and the presence of toxic components in crude oil such as polyaromatic hydrocarbons (PAHs, hereafter) which are carcinogenic to humans, can bioaccumulate in marine organisms and persist in the environment for years (Mearns et al. 2010).

During the Deepwater Horizon (DwH, hereafter) oil spill (2010) 4.9 million barrels of oil were released to the Gulf of Mexico from the Macondo well MC252 (Beyer et al. 2016) and 4$14.4 \%$ of the oil settled on the deep seabed (Chanton et al. 2015). Contact of oil with sediment, particularly coastal sediments, is highly undesirable because it can cause negative environmental impacts if oil is stranded in sensitive areas such as salt marshes or on beaches for human use (Hayworth et al. 2015; Pietroski et al. 2015). Dissolved and dispersed oil in the marine environment can adsorb onto suspended particulate matter such as sediment particles, organic debris or actual organisms to form aggregates (Gong et al. 2014a). Particle size can influence the amount of oil adsorbed as a consequence of its relative surface area (Pignatello 1998). Fine sediments, with larger surface area per unit volume, can take up more oil than coarser ones, with lower surface area. Hydrophobic pollutants readily adsorb onto organic matter in sediments, organic carbon (OC) content has been shown to be the main driver of organic pollutant sorption to sediments (Xing et al. 1996). Therefore, OC-rich sediments are expected to uptake more organic pollutants than sediments low in OC. Other variables that affect sorption of organic compounds onto sediments include temperature, salinity and pressure (Piatt et al. 1996; Marini and Frapiccini 2013; Zhao et al. 2015). Oil-sediment aggregation can influence oil fate in the marine environment. Oil-sediment aggregates can be transported to the seabed by sedimentation or be mobilised horizontally by currents, waves and winds to locations far from the oil spill source (Bandara et al. 2011).

Oil spill models are tools used in prevention and response operations in the oil and gas industry to predict the trajectories and fates of spilled oil in the environment (Reed et al. 1999). A component of oil spill models is the interaction of oil with sediment particles and their subsequent fate. To our knowledge, the Oil Spill Contingency and Response (OSCAR) model 
uses the algorithms from Bandara et al. (2011). This is an algorithm but considers oil droplets as a single pollutant, and as such does not capture the distribution of single component interactions. A useful property to implement in these models is the water-sediment distribution coefficients $\left(K_{\mathrm{D}}\right.$; volume/mass). The coefficient represents the affinity of a pollutant for a particular sediment and is defined as (Matthies 2011):

$$
K_{D}=\frac{C_{S}}{C_{W}} \quad \text { Eq. } 1
$$

where $C_{\mathrm{S}}$ (mass/mass) and $C_{\mathrm{W}}$ (mass/volume) are the concentrations of a pollutant in sediment and seawater, respectively. $K_{\mathrm{D}}$ coefficients are specific to each pollutant-sediment combination since each sediment has different properties (e.g. particle size distribution, organic matter content, etc.) (Matthies 2011). Further to this, it has been previously shown that $K_{\mathrm{D}}$ can vary by orders of magnitude for a given compound under different environmental conditions (Baes and Sharp 1983). Modelling $K_{\mathrm{D}}$ is difficult due to the large number of variables that influence it and, as such, empirical determination is the most accurate method. Determination of $K_{\mathrm{D}}$ of PAHs is relevant because of their toxicity, recalcitrance and importance in environmental legislation (Yamada et al. 2003; Office of Solid Waste 2008; Mason et al. 2014).

Dispersants are employed during oil spills to lower the interfacial tension between water and oil to facilitate the breaking up of oil slicks into smaller droplets that can then be more rapidly degraded both physically and biologically (Fingas 2002). Following the $D w H$ oil spill, extensive work was undertaken to evaluate the effects of Corexit dispersants (those used during the spill) on oil-suspended particulate matter aggregation (Gong et al. 2014b, a; Zhao et al. 2016). A recent study has shown that different dispersant formulations selectively solubilise and affect the sorption of specific fractions of crude oil (Zhao et al. 2016). For example, Corexit 9500A preferentially dispersed $\mathrm{C}_{12}-\mathrm{C}_{16}$ and $\mathrm{C}_{20}-\mathrm{C}_{28}$ n-alkanes whereas Corexit 9527A favoured $\mathrm{C}_{10}-\mathrm{C}_{20} n$-alkane dispersion. Consequently, the need arises to characterise the effects of other ready-to-use and commercially available dispersants on oil-sediment interactions. Zhao et al. (2015) reported that Corexit 9500A has contrasting effects on the extent to which hydrocarbons adsorb onto sediments; (1) Corexit 9500A increased the solubility of hydrocarbons in seawater and (2) surfactants in Corexit 9500A adsorb to sediment particles and create additional adsorption sites for hydrocarbons.

Given that dispersant application is an important oil spill response strategy that directly affects physicochemical properties of hydrocarbons in the marine environment (Fingas 2002), further 
understanding of its effects on hydrocarbon-sediment interactions is important (Gong et al. 2014a). Over- or underestimation of sorption to sediments may lead to inappropriate choice of resource allocation in the event of an oil spill whereby hydrocarbon uptake by different sediment types may be erroneously estimated.

The aim of this work was to determine the effect of Superdispersant-25 (SD25, hereafter), a dispersant stockpiled in the United Kingdom, on the sorption dynamics of naphthalene and phenanthrene (NAP and PHE, hereafter, respectively) as well as its own sorption dynamics in three sediment types from North Scotland. It was hypothesised that (1) SD25 and PAHs would be taken up to a greater extent by fine than by coarse sediment, (2) an increase in SD25 concentration would favour the partitioning of PHE to the aqueous phase more than that of NAP due to differences in water-solubility and (3) SD25 application would increase PAH adsorption onto sediments by increasing PAH solubility and the creation of additional adsorption sites on the sediment itself by adsorbing to it.

\section{Materials and methods}

\section{$121 \quad 2.1 \quad$ Sediments and artificial seawater}

122 Sediment samples were collected from the top $10 \mathrm{~cm}$ of sediment from the Faroe-Shetland 123 Channel (1000 m; FSC, hereafter) aboard MRV Scotia in May 2014 (61³5.02`N, 4¹4.64’W), 124 Stonehaven Bay (14 m; SB, hereafter) aboard MRV Temora in June 2016 (56 58'18"N, $\left.1252^{\circ} 11^{\prime} 3 " \mathrm{~W}\right)$ and the Ythan estuary (intertidal; YE, hereafter) in December $2016\left(57^{\circ} 18^{\prime} 14^{\prime \prime} \mathrm{N}\right.$, $1261^{\circ} 59 ' 25^{\prime \prime}$ ) (Fig. 1). Sampling methods were maxi-corer (OSIL, United Kingdom), Van Veen 127 grab and manual collection for FSC, SB and YE sediments, respectively. Sediments were 128 autoclaved at $121^{\circ} \mathrm{C}$ for $21 \mathrm{~min}$ at $100 \mathrm{kPa}$ and oven dried at $60^{\circ} \mathrm{C}$ for three days to minimise 129 microbial activity prior to carrying out experiments. Artificial seawater was prepared by adding 130 pre-oven dried (at $130^{\circ} \mathrm{C}$ for $24 \mathrm{~h}$ ) Seamix Artificial Sea Salt (Peacock Salt, United Kingdom) 131 at $3.4 \%$ (mass/volume) to ultra-pure (type 1) water and magnetically stirring for $8 \mathrm{~h}$. 


\subsection{Sediment characterisation}

Sediments were characterised in terms of particle size distribution and carbon content. YE and SB sediments were oven-dried at $105^{\circ} \mathrm{C}$ overnight and sieved through mesh sizes of 2000 , 1000, 500, 250, 120 and $63 \mu \mathrm{m}$. Statistical analyses of particle size distribution were carried out using Gradistat v.8 (Blott and Pye 2001). FSC sediments were oven-dried at $105^{\circ} \mathrm{C}$ overnight and then wet sieved through a $63 \mu \mathrm{m}$ mesh to separate coarse (>63 $\mu \mathrm{m})$ from fine sediment $(<63 \mu \mathrm{m})$. Coarse sediment was then analysed as described above and fine sediment was analysed using the hydrometer method (Ashworth et al. 2001) and statistical analysis of particle size distribution was performed using the Hydrometer Particle Size Calculator (Natural $\underline{\text { Resources Conservation Service - United States Department of Agriculture Hydrometer }}$ Particle Size Calculator - ASTM No. 1).

To determine carbon content, sediments were initially oven-dried at $60^{\circ} \mathrm{C}$ for three days. Thereafter, sediments were mechanically milled. Subsequently, total carbon content was determined using a NA2500 elemental analyser (Carlo Erba Instruments). Total OC content was determined by acidifying sediment with $10 \% \mathrm{HCl}$ and oven-dried at $60^{\circ} \mathrm{C}$ for three days and subsequently analysed by elemental analysis. Total inorganic carbon content was determined by difference between total carbon and total OC.

\subsection{Superdispersant-25 measurements and critical micelle concentration determination}

152 Three independent stock solutions of SD25 in artificial seawater at 100 and $1000 \mathrm{mg} \mathrm{l}^{-1}$ were 153 prepared and equilibrated. Dilutions were performed to obtain solutions at concentrations of 0 , $1540.25,5,10,25,50,100,200,300,400,500$ and $1000 \mathrm{mg} \mathrm{l}^{-1}$. Thereafter, seawater surface 155 tension measurements were performed using a tensiometer (White's instruments) fitted with a 156 du Nouy ring to calibrate the response of surface tension to SD25 concentration. The apparent critical micelle concentration was calculated as the inflexion point in seawater surface tension as a function of SD25 concentration, as described elsewhere (Gong et al. 2014). 


\subsection{Effect of Superdispersant-25 on aqueous solubility of PAHs}

161 Saturated solutions of PHE and NAP with increasing SD25 were prepared to assess the influence of initial SD25 concentration in seawater ([SD25] $]_{\mathrm{Sw}, 0}$, hereafter) on PAH solubility in seawater. Briefly, $200 \mathrm{mg}$ of each PAH were added to separate $70 \mathrm{ml}$ glass vials and stock solutions of seawater and SD25 were mixed to achieve concentrations in the range 0-1000 mg $\mathrm{I}^{-1}$ and added to the vials. The mixtures were then equilibrated by magnetic stirring at $20^{\circ} \mathrm{C}$ in complete darkness for three days to ensure dynamic equilibrium. $20^{\circ} \mathrm{C}$ was chosen as past $\underline{\text { sorption dynamics and sediment hydrocarbon biodegradation literature has been undertaken at }}$ this temperature. The experiments were performed in complete darkness to prevent photodegradation of PAHs. After equilibration, solutions were centrifuged in glass centrifuge tubes at $3000 \mathrm{rpm}$ for 10 mins such that suspended PAH is removed from solution and only dissolved PAH remained. 25 and $50 \mathrm{ml}$ of NAP and PHE solutions, respectively, were then sequentially liquid-liquid extracted three times with $10 \mathrm{ml}$ dichloromethane using pristane as an internal extraction standard $\left(100 \mu \mathrm{l}\right.$ at $\left.20 \mu \mathrm{g} \mathrm{ml}^{-1}\right)$. PHE extracts were then evaporated to approximately $5 \mathrm{ml}$ under nitrogen and analysed by gas chromatography with flame ionisation detection. NAP extracts were injected immediately after extraction. Further analysis details can be found elsewhere (Perez Calderon et al. 2018b).

\subsection{Superdispersant-25 uptake by sediments}

179 Sorption of SD25 by sediments was evaluated in two stages, (1) where SD25 solutions were 180 equilibrated with sediment and (2) where supernatant solutions after equilibration were 181 replaced with clean seawater. These were defined as adsorption and desorption stages, 182 respectively. Pre-treated sediment $(2.5 \mathrm{~g})$ were added to $15 \mathrm{ml}$ Pyrex centrifuge tubes with 183 Teflon-lined caps. $12 \mathrm{ml}$ of SD25 in artificial seawater solutions at concentrations of 0, 10, 20, $30,100,175,250,375$ and 500 , and $1000 \mathrm{mg} \mathrm{l}^{-1}$ were prepared and added to the centrifuge tubes. Thereafter, these were incubated in a horizontal shaker at $200 \mathrm{rpm}$ for three days at $20^{\circ} \mathrm{C}$ in complete darkness. Vials were then centrifuged at $3000 \mathrm{rpm}$ for $10 \mathrm{mins}$ and $3 \mathrm{ml}$ of supernatant was sampled to measure surface tension. The remaining supernatant was replaced with artificial seawater and incubated a further three days in complete darkness. Samples were centrifuged again at $3000 \mathrm{rpm}$ for 10 mins and surface tension measurements taken. SD25 concentration was calculated from the calibration curves prepared for the critical micelle 
concentration determination experiment. Measurements were conducted for each sediment type in triplicate.

\subsection{PAH sorption by sediments and effect of Superdispersant-25}

The effect of SD25 concentration on PAH sorption by sediments was evaluated in two stages as described in section $2.5 .12 \mathrm{ml}$ solutions containing $0.40 \mathrm{mg} \mathrm{PHE}^{-1}$ or $3.85 \mathrm{mg} \mathrm{NAP} \mathrm{l}^{-1}$ and SD25 at $0,10,20,30,100,200,300 \mathrm{mg}^{-1}$ in artificial seawater were prepared and added to $15 \mathrm{ml}$ glass centrifuge tubes lined with Teflon-lined caps. Samples were incubated and centrifuged as described in section 2.5. PAH concentration in seawater was determined by UVvis spectroscopy using a Lambda 25 UV/VIS Spectrometer (PerkinElmer). UV-vis spectra were measured with a $10 \mathrm{~mm}$ path-length quartz cuvette over the range $200-400 \mathrm{~nm}$. PHE and NAP concentrations were calculated from absorbances at 251 and $275 \mathrm{~nm}$, respectively. 5point calibration curves were prepared for each PAH and blanks with seawater only were ran after every 5 samples. Absorbances of blanks and solutions of SD25 in seawater and sediment were subtracted from measured values.

\subsection{Chemicals}

PHE (99\%), NAP (99\%), pristane (99\%) and dichloromethane (HPLC grade) were acquired from Sigma Aldrich (United Kingdom). Superdispersant-25 was acquired from Oil Technics (United Kingdom).

\subsection{Calculations and statistical modelling}

$K_{\mathrm{D}}$ can be envisaged as being composed of two terms to evaluate the contributions of surfactants to the sorption of PAHs to sediments (Lu and Zhu 2012):

$$
K_{D}=\frac{C_{s e d}}{C_{s w}}=K_{O C} f_{O C}+K_{s f} Q_{s f} \quad \text { Eq. } 2
$$

where $C_{\text {sed }}$ is the PAH concentration in sediment $\left(\mathrm{mg} \mathrm{g}^{-1}\right), C_{\mathrm{sw}}$ is the PAH concentration in seawater $\left(\mathrm{mg} \mathrm{l}^{-1}\right), K_{\mathrm{oc}}$ is the OC-normalised PAH distribution coefficient $\left(\mathrm{ml} \mathrm{g}^{-1}\right)$, calculated as 
$2180.35 K_{\text {ow }}$ (Octanol-water coefficient) (Seth et al. 1999), $f_{\text {oc }}$ is the OC fraction of the sediment, $K_{\mathrm{sf}}$ is the surfactant-normalised PAH distribution coefficient $\left(\mathrm{ml} \mathrm{g}^{-1}\right)$, defined here as $K_{\mathrm{SD} 25}$ (for $\mathrm{SD} 25)$ and $Q_{\mathrm{sf}}$ is the sediment-adsorbed surfactant concentration $\left(\mathrm{mg} \mathrm{g}^{-1}\right)$, defined here as $Q_{\mathrm{SD} 25}$ and including all components of the SD25 formulation. Analyte concentrations in sediment were calculated by subtracting the concentrations measured in in artificial seawater from initial concentrations added. For calculating of $K_{\mathrm{D}}$ values when no analyte was detected in the aqueous phase, a value of $0.001 \mathrm{mg}^{-1}$ was used as the concentration in seawater.

Response of sorption variables to SD25 concentration were modelled using locally weighed regressions due to the non-linearity of the data, where sorption variables were the response variable and SD25 concentration in either water or sediment was the explanatory variable, subset by PAH, sediment type and experimental stage (adsorption: first inoculation; desorption: replacement of supernatant with clean seawater). Briefly, the model fits a polynomial surface determined by $\mathrm{PAH}$ solubility. $Q_{\mathrm{SD} 25}$ values were estimated from locally weighed regressions from experiments described in Section 2.5. All statistical analysis was undertaken using $\mathrm{R}(\mathrm{R}$ Development Core Team 2017) and the library ggplot2 was used for locally weighted regression analysis (Wickham and Chang 2009).

\section{Results}

\subsection{Sediment characterisation and Superdispersant-25 critical micelle concentration}

FSC, SB and YE sediments were classified as silty loam, medium and fine sands, respectively. Details of particle size distribution and carbon content of the sediments analysed can be found in Table 1. The critical micelle concentration of Superdispersant-25 in artificial seawater $(\mathrm{T}=$ $20^{\circ} \mathrm{C}, \mathrm{S}=34$ ) was $5.8 \mathrm{mg} \mathrm{l}^{-1}$ (Fig. 2).

\subsection{Effect of Superdispersant-25 concentration on PAH solubility in seawater}

Solubility of PHE in artificial seawater linearly increased from $0.57 \pm 0.20$ to $4.44 \pm 1.32 \mathrm{mg}$ $\mathrm{l}^{-1}$ from 0 to $250 \mathrm{mg} \mathrm{SD} 25 \mathrm{l}^{-1}$ and decreased to $2.07 \pm 1.66 \mathrm{mg} \mathrm{l}^{-1}$ at $1000 \mathrm{mg} \mathrm{SD} 25 \mathrm{l}^{-1}$. Solubility 
of NAP in artificial seawater remained constant from 0 to $1000 \mathrm{mg} \mathrm{SD} 25 \mathrm{l}^{-1}(10.00 \pm 1.89$ and 272 $11.18 \pm 0.91 \mathrm{mg} \mathrm{l}^{-1}$, respectively, Fig. 3).

\subsection{Dispersant sorption onto sediments}

SD25 uptake by sediments differed across sediment type and [SD25]sw,0 range (Fig. 4). At [SD25] $]_{\mathrm{Sw}, 0}<175 \mathrm{mg} \mathrm{l}^{-1}$ all sediments took up all SD25 from solution and no evidence for desorption back into solution was detected in the desorption stage. In FSC sediment, uptake of all SD25 was observed across the range of $[\mathrm{SD} 25]_{\mathrm{sw}, 0}$ and no desorption was detected at any

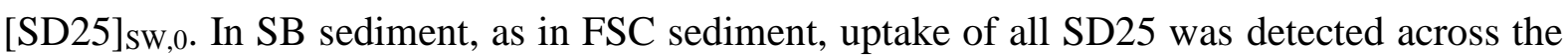
$[\mathrm{SD} 25]_{\mathrm{Sw}, 0}$ range tested. However, SD25 desorption was apparent at [SD25]sw,0>250 mg SD $\mathrm{l}^{-1}$. At [SD25] $]_{\mathrm{Sw}, 0}>175 \mathrm{mg} \mathrm{SD} 25 \mathrm{l}^{-1}$, YE sediment uptake of SD25 plateaued at $\sim 1.5 \mathrm{mg} \mathrm{g}^{-1}$, and desorption could not be inferred also due to high variability of [PHE].

\subsection{Effect of Superdispersant-25 on PAH uptake by sediments}

$K_{\mathrm{D}}$ values of NAP and PHE as a function of $Q_{\mathrm{SD} 25}$ to the sediments investigated varied with sediment type and experimental stage (adsorption or desorption) (Fig. 5). During the adsorption stage, SD25 application increased $K_{\mathrm{D}}$ values in YE and SB sediments but not in FSC sediment. As $Q_{\mathrm{SD} 25}$ increased, $K_{\mathrm{D}}$ values of both PAHs to $\mathrm{SB}$ and $\mathrm{YE}$ sediments increased. Desorption stage $K_{\mathrm{D}}$ values of both PAHs decreased relative to the adsorption stage. Desorption stage $K_{\mathrm{D}}$ values decreased with $Q_{\mathrm{SD} 25}$ in FSC sediments and increased in other sediment types, except for NAP in YE sediment, where no effect of $Q_{\mathrm{SD} 25}$ was apparent. The adsorption of PAHs to sediment-adsorbed SD25 was evaluated by comparing $K_{\mathrm{SD} 25}$ to $Q_{\mathrm{SD} 25}$ (Fig. 6). Overall, no clear patterns emerged for $K_{\mathrm{SD} 25}$ as a function of $Q_{\mathrm{SD} 25}$ during either the adsorption or desorption stages.

\section{Discussion}

\section{$270 \quad 4.1 \quad$ Key findings}

271 SD25 had contrasting effects on the water-solubility of PHE and NAP. PHE water-solubility was increased from SD25 concentration as low as $10 \mathrm{mg} \mathrm{l}^{-1}$ but NAP water-solubility was not 
affected by SD25, even at $1000 \mathrm{mg} \mathrm{l}^{-1}$. Sorption of SD25 by sediments varied by sediment type. FSC sediment took up all SD25 in solution across the [SD25] $]_{\mathrm{Sw}, 0}$ range tested and no desorption of SD25 was detected. In contrast, in SB and YE sediments SD25 desorption was apparent in experiments with [SD25] $]_{\mathrm{sw} 0}>250 \mathrm{mg} \mathrm{l}^{-1}$. Sorption dynamics of PAHs varied by $\mathrm{PAH}$, sediment type and $Q_{\mathrm{SD} 25} Q_{\mathrm{SD} 25}$ increased $K_{\mathrm{D}}$ values of both PAHs in SB and YE sediments but did not have a clear effect on the adsorption of either PAH in FSC sediments. Desorption stage $K_{\mathrm{D}}$ values generally decreased with respect to the adsorption stage. There was no clear trend of PAH sorption to sediment-adsorbed dispersant as a function of $Q_{\mathrm{SD} 25}$.

\subsection{Effect of dispersant on PAH solubility in seawater}

283 SD25 application increased the water-solubility of PHE but not of NAP. PHE water-solubility could be increased up to seven-fold with dispersant application at $250 \mathrm{mg} \mathrm{l}^{-1}$ (Fig. 3). However, at SD25 concentration above $250 \mathrm{mg} \mathrm{l}^{-1}$, PHE solubility was reduced implying that SD25 may have an optimal concentration to mobilise target pollutants. SD25 application, even at SD25 concentration $<30 \mathrm{mg}^{-1}$, resulted in increased PHE solubility indicating that PAHs such as PHE can be readily dissolved and dispersed in the water column. Increasing the solubility of PAHs in the water column by dispersant facilitates their dilution and dispersion in the marine environment (Fingas 2002) which can aid in long-term removal. Hydrocarbons have been shown to photodegrade more rapidly when chemically dispersed with Corexit $9500 \mathrm{~A}$ than in its absence (Zhao et al. 2016). Chemical dispersion may negatively impact or have no effect on hydrocarbon biodegradation in the water column by modifying the microbial community composition and selecting for potential dispersant-degrading bacteria Colwellia and not Marinobacter, a natural hydrocarbon degrader (Kleindienst et al. 2015). The overall benefits of dispersant to the marine environment remain debated although it can be beneficial given specific circumstances (Prince 2015).

[SD25 $]_{\mathrm{Sw}, 0}$ up to $1000 \mathrm{mg} \mathrm{l}^{-1}$ did not enhance NAP solubility $\left(\sim 11 \mathrm{mg} \mathrm{l}^{-1}\right)$ although there have been reports of higher water-solubility of NAP in seawater without surfactant addition (23.1 $\mathrm{mg} \mathrm{l}^{-1}$ at $25^{\circ} \mathrm{C}$ (Adelman 1977) and $28 \mathrm{mg} \mathrm{l}^{-1}$ at $20^{\circ} \mathrm{C}$ (Zhao et al. 2015)). Previous work using SD25 has shown that SD25 has limited effect on NAP mobility into sediments (Perez Calderon et al. 2018b, c, a). In contrast, investigations into NAP water-solubility have shown that Corexit 9500A can linearly increase its solubility in seawater. Zhao et al. (2015) reported that $200 \mathrm{mg}$ 
Corexit 9500 $\mathrm{A}^{-1}$ increased NAP solubility in seawater from 28 to $36 \mathrm{mg} \mathrm{l}^{-1}$. These apparent contradictions illustrate that different commercial dispersants and seawater types may solubilise specific hydrocarbons to different extents. Therefore, conclusions drawn from work using one oil-dispersant-seawater system may not be transferable to another system with a different dispersant or seawater. This is important given that a large body of literature has been produced following the $\mathrm{DwH}$ oil spill using Corexit dispersants which may only be relevant in the context of the Macondo oil-Corexit dispersant combination. Therefore, further research is required into how different dispersants affect oil-water interactions.

\subsection{Superdispersant-25 sorption by sediments}

All SD25 across the concentration range tested was adsorbed onto FSC sediment and did not desorb following water replacement (Fig. 4). This finding highlights the strong uptake capacity of SD25 by fine deep-sea sediments. Subsea application of dispersant, as witnessed during the $D w H$ oil spill resulted in significant amounts of dispersant ending up on the seabed (White et al. 2014). The proposed pathways of dispersant deposition on the Gulf of Mexico seabed are thought to be surface sorption and settling of dispersant-suspended particle aggregates (Gong et al. 2014b; White et al. 2014). Sorption of non-polar hydrophobic pollutants to sediments is dependent on organic matter content and if it is above $0.01 \%$, it may take up the majority of the pollutant as opposed to the mineral component of the sediment (Pignatello 1998). In this experiment, this was verified for SD25 as maximum uptake was observed by high OCcontaining sediments (FSC and $\mathrm{SB}$ ) as opposed to low OC-containing sediment (YE). Desorption of SD25 was detected in SB but not in FSC sediment potentially due to the difference in percentage of fines between sediment types (Fig. 4). Dispersant has been found to persist in deep-sea sediments and corals for over four years following the $D w H$ oil spill and that environmental conditions in deposition sites influenced its residence time (White et al. 2014). Results here suggest that responders should consider sediment characteristics as part of the decision-making process for dispersant application in the marine environment due to the capacity of dispersant to adsorb to marine sediments, particularly when sediments are fine or OC-rich. For example, in a hypothetic offshore well blowout scenario, SD25 application near fine sediments, such as FCS sediments, may enhance uptake of SD25, oil droplets and dissolved hydrocarbons more readily than other sediments. This can yield more negative effects for benthic ecosystems than application at surface waters where oil and dispersant are less 
likely to come into contact with the seabed. On the other hand, if the seabed is sandy, application of SD25 near the seabed is less likely to result in adsorption of hydrocarbons although it may enhance entrainment via advective pore-water transport (Perez Calderon et al. 2018c). This is particularly important if protected species such as sand eels are near the target site for SD25 application as they are sensitive to oil (Heath and Bailey 1994).

\subsection{Effect of dispersant on PAH uptake by sediments}

$343 K_{\mathrm{D}}$ values of NAP and PHE varied with sediment type, $Q_{\mathrm{SD} 25}$ and experimental stage to varying 344 extents (Figs 5,Fig. 6). In FSC sediments, $Q_{\mathrm{SD} 25}$ did not affect $K_{\mathrm{D}}$ values of either PAH in the 345 adsorption stage which is likely due to the high proportion of fines (70.8\%) and OC (1.67\%). 346 In contrast, in sandy sediments with a lower proportion of fines such as SB and YE sediments, 347 uptake increased with $Q_{\mathrm{SD} 25}$ suggesting that surfactant sorption may create new adsorption sites 348 in coarser sediments as previously reported for PHE in sandy loam and loamy sand using 349 Corexit 9500A (Gong et al. 2014b). Corexit 9500A in solution (18 $\left.\mathrm{mg}^{-1}\right)$ has been shown to 350 have limited effects on NAP sorption to sandy loam and loamy sand, increasing in NAP uptake 351 by sediment of $2.9 \%$ and $3.3 \%$, respectively (Zhao et al. 2015). Here, the highest uptake of NAP was measured in YE sediments at $\sim 0.8 \mathrm{mg} \mathrm{SD} 25 \mathrm{~g}^{-1}$ (Fig. 5) although no effect of SD25 on naphthalene solubility was apparent (Fig. 4). However, no NAP was detected in the aqueous phase in these samples and the default value of $0.001 \mathrm{mg} \mathrm{l}^{-1}$ was assigned which may have skewed the $K_{\mathrm{D}}$ values of NAP in these samples. Desorption-phase $K_{\mathrm{D}}$ values across sediments for both NAP and PHE decreased indicating that adsorption of both NAP and PHE in these sediments was partially reversible. Increasing $Q_{\mathrm{SD} 25}$ reduced desorption stage $K_{\mathrm{D}}$ values of NAP in FSC sediments suggesting that SD25 uptake increased the partitioning of NAP to the aqueous phase. In contrast, desorption stage $K_{\mathrm{D}}$ values of NAP in SB or YE did not vary with $Q_{\text {SD25 }}$ suggesting that sediment-adsorbed SD25 does not retain NAP in sandy sediments with seawater exchange.

The effect of $Q_{\mathrm{SD} 25}$ on the desorption of PHE was similar to that in the adsorption stage in SB and YE sediments suggesting that PHE remains more strongly adsorbed to marine sediments with increasing $Q_{\mathrm{SD} 25}$ than NAP. Desorption stage $K_{\mathrm{D}}$ values of PHE in YE sediments were approximately one order of magnitude higher than those of NAP (Fig. 5) suggesting that, even in the absence of fines, PHE may remain strongly adsorbed onto sandy sediments. Strong 
adsorption of PAHs to silty loams following continuous desorption experiments has been recently reported (Duan et al. 2018). The authors also reported that addition of Corexit 9500A and SPC 100 increased desorption of PAHs and to a lesser extent that of alkanes. Similarly, Gong et al. (2014) reported increased hysteresis of PHE in sandy loam and loamy sand at increasing Corexit 9500A, suggesting that SD25 may be less effective at desorbing NAP and PHE from marine sediments although it does increase their solubility in seawater. The contribution of $Q_{\mathrm{SD} 25}$ to $K_{\mathrm{SD} 25}$ values of either $\mathrm{PAH}$ in this experiment was unclear. Previous research showed increased adsorption of organic pollutants to sediment-bound dodecylpyridinium bromide, even in humic acid with $\sim 50 \%$ OC where OC would be expected to adsorb the majority of the pollutant ( $\mathrm{Lu}$ and $\mathrm{Zhu} 2012$ ). This difference may arise from the use of a different dispersant formulation (SD25).

Disparity in response to SD25 application has been observed in hydrocarbon pore-water transport experiments where NAP and PHE were mixed with hydrocarbons from other fractions (BTEX, aliphatics and other PAHs) (Perez Calderon et al. 2018b, c, a). The effect of SD25 on NAP mobility in sediments in these experiments was limited, suggesting a similar "behaviour" to that observed here. In contrast, PHE mobility in sediments increased with SD25 application in these experiments. The solubilising effect of SD25 was masked by the high water-solubility of NAP but was apparent for PHE, even when in the same system. Other hydrocarbons were found to not be affected by SD25-application (e.g. BTEX) which are also highly water-soluble, suggesting this is the key property that governs the extent to which SD25 affects hydrocarbons in these systems.

388 The findings here show the effects of SD25 on PAH-sediment-seawater dynamics in three 389 sediments from the North Sea and FSC. Adsorption of PAHs to sediments was facilitated by 390 SD25 application. The driving mechanism appeared to be the solubilising effect of SD25 on 391 PAHs as $Q_{\mathrm{SD} 25}$ did not appear to drive PAH adsorption onto FSC sediments, suggesting that 392 SD25 application in a subsea blowout in the FSC may not increase sorption of PAHs but may 393 result in SD25 adsorption to sediment, where dispersants can persist for years (White et al. 394 2014) and affect microbial community composition (Ferguson et al. 2017; Perez Calderon et al. 2018b). In contrast, increased uptake of PAHs by SB and YE sediments with increasing $Q_{\mathrm{SD} 25}$ suggest that less sorptive sediments (i.e. with lower OC and fines percentages) may increase their uptake of PAHs through sediment-adsorbed SD25. It is important to note that sediments here were sterilised and artificial seawater used and such bacterial activity in the sediments was reduced. Consequently, the role of biodegradation, biosurfactant production and 
transparent exopolymeric particle production has not been considered here. These processes may have a marked effect on sorption dynamics. For example, biodegradation reduces surfactant concentration in media through microbial metabolism (Brakstad et al. 2018), which may limit hydrocarbon uptake by sediments. Biosurfactant production increases PAH bioavailability and can enhance biodegradation ( $\mathrm{Lu}$ et al. 2011), which can decrease their concentration in sediments. Finally, transparent exopolymeric particles (colloidal organic carbon structures containing acidic polysaccharides) play a key role in adsorbing particulates in the wider ocean (Rochelle-Newall et al. 2010). They can act as binding sites for dispersant and remove surfactants and PAHs from solution as suggested in the MOSSFA hypothesis, whereby marine snow acted as a pathway for deposition of hydrocarbons and dispersant on the deep seabed after $D w H$ (Passow 2016). The role of these biological processes cannot be ignored in a real oil spill. However, the focus here was on the physical interactions between PAHs, dispersants and sediments. Further research is required to evaluate the physicochemical processes investigated here in conjunction with biological processes how the sorption dynamics of other, larger PAHs are affected by dispersant application.

\section{Conclusions}

The present study evaluated the sorption dynamics of PHE and NAP in three marine sedimentsseawater systems and the effect of SD25 concentration on this process. The main findings of the study were:

1. Dispersant increased the solubility of PHE in seawater up to seven-fold but had no effect on the solubility of NAP. This contrasts with previous work, where NAP solubility was enhanced with Corexit 9500A, suggesting that different dispersant formulations can selectively solubilise specific PAHs in seawater. Dispersant choice should be considered by responders to account for selective solubilisation of toxic chemicals such as PAHs and the potential knock-on effects this choice may have on the wider marine environment, e.g. the seabed as discussed here.

2. FSC and SB sediments adsorbed all SD25 across the concentration range tested (up to $\sim 5 \mathrm{mg} \mathrm{g}^{-1}$ ) but no desorption could be measured in FSC sediments suggesting SD25 can remain strongly bound to fine sediments. In YE sediments, sorption of SD25 was more limited (up to $\sim 1.5 \mathrm{mg} \mathrm{g}^{-1}$ ) and desorption of SD25 was highly variable. 

455

3. Sorption dynamics of both PAHs were affected by sediment type and $Q_{\mathrm{SD} 25}$ to different extents. $K_{\mathrm{D}}$ values decreased in the desorption stage compared to the adsorption stage for both PAHs. $Q_{\mathrm{SD} 25}$ increased adsorption of both PAHs in SB and YE but not FSC sediments. The finding suggests that SD25 increased sediment uptake of PAHs but did not retain them strongly adsorbed to the sediment following water replacement.

4. $Q_{\mathrm{SD} 25}$ did not have a clear effect on $K_{\mathrm{SD} 25}$ values of either PAH, suggesting that sediment-adsorbed SD25 increases the adsorption of these PAHs to sediment but not onto sediment-adsorbed SD25.

439 The results provide evidence of SD25 influence on the sorption dynamics of PAHs in marine sediments, which varies by sediment type and PAH. The results highlight the importance of considering the relationship between SD25 and sorption dynamics on the fate of PAHs in marine sediments following an oil spill. Further research into the sorption dynamics of PAHs across commercial dispersants, sediment types, within hydrocarbon mixtures and biotic interactions is required to evaluate the potential effects of dispersant on oil-sediment interactions.

Acknowledgements: LJP was funded through MarCRF funds for a $\mathrm{PhD}$ project designed by UW, JA and AG and awarded to LJP. The authors acknowledge the assistance of Mike Mcgibbon in analysing carbon content, the crews of the MRV Scotia and MRV Temora for sample collection. Dr. Hedda Weitz and Prof. Graeme Patton are thanked for facilitating access to laboratory space and equipment.

\section{References}

454 Adelman IR (1977) Effects of Pollutants on Aquatic Organisms. J Environ Qual 6:474. doi: $10.2134 /$ jeq1977.00472425000600040037x

Ashworth J, Keyes D, Kirk R, Lessard R (2001) Standard procedure in the hydrometer method for particle size analysis. Commun Soil Sci Plant Anal 32:633-642. doi: 10.1081/CSS-100103897

Baes CF, Sharp RD (1983) A proposal for estimation of soil leaching and leaching constants for use in assessment models. J Environ Qual 12:17. doi: 10.2134/jeq1983.00472425001200010003x

Bandara UC, Yapa PD, Xie H (2011) Fate and transport of oil in sediment laden marine waters. J Hydroenvironment Res 5:145-156. doi: 10.1016/j.jher.2011.03.002 
Beyer J, Trannum HC, Bakke T, et al (2016) Environmental effects of the Deepwater Horizon oil spill: A review. Mar Pollut Bull 110:28-51. doi: 10.1016/j.marpolbul.2016.06.027

Blott SJ, Pye K (2001) GRADISTAT: a grain size distribution and statistics package for the analysis of unconsolidated sediments. Earth Surf Process Landforms 26:1237-1248. doi: 10.1002/esp.261

Brakstad OG, Størseth TR, Brunsvik A, et al (2018) Biodegradation of oil spill dispersant surfactants in cold seawater. Chemosphere 204:290-293. doi: 10.1016/j.chemosphere.2018.04.051

Chanton J, Zhao T, Rosenheim BE, et al (2015) Using natural abundance radiocarbon to trace the flux of petrocarbon to the seafloor following the Deepwater Horizon oil spill. Environ Sci Technol 49:847-854. doi: 10.1021/es5046524

Dixon T (2015) Annual survey of reported discharges and releases attributed to vessels and offshore oil and gas installations operating in the united kingdom's exclusive economic zone (UK EEZ) 2014. Advisory Committee on Protection of the Sea. Cambridge, UK

Duan J, Liu W, Zhao X, et al (2018) Study of residual oil in Bay Jimmy sediment 5 years after the Deepwater Horizon oil spill: Persistence of sediment retained oil hydrocarbons and effect of dispersants on desorption. Sci Total Environ 618:1244-1253. doi: 10.1016/j.scitotenv.2017.09.234

Ferguson RMW, Gontikaki E, Anderson JA, Witte U (2017) The variable influence of dispersant on degradation of oil hydrocarbons in subarctic deep-sea sediments at low temperatures $\left(0-5^{\circ} \mathrm{C}\right)$. Sci Rep 7:2253. doi: 10.1038/s41598-017-02475-9

Fingas MF (2002) A review of literature related to oil spill dispersants especially relevant to Alaska. Environmental Technology Centre. Anchorage, USA

Gong Y, Zhao X, Cai Z, et al (2014a) A review of oil, dispersed oil and sediment interactions in the aquatic environment: Influence on the fate, transport and remediation of oil spills. Mar Pollut Bull 79:16-33. doi: 10.1016/j.marpolbul.2013.12.024

Gong Y, Zhao X, O'Reilly SE, et al (2014b) Effects of oil dispersant and oil on sorption and desorption of phenanthrene with Gulf Coast marine sediments. Environ Pollut 185:240-249. doi: 10.1016/j.envpol.2013.10.031

Hayworth JS, Prabakhar Clement T, John GF, Yin F (2015) Fate of Deepwater Horizon oil in Alabama's beach system: Understanding physical evolution processes based on observational data. Mar Pollut Bull 90:95-105. doi: 10.1016/j.marpolbul.2014.11.016

Heath MR, Bailey MC (1994) The impact of the Braer oil spill on sandeel availability to seabirds around Shetland. The effects of the oil spill on the growh and development of early life history stages. Marine Laboratory. Aberdeen, UK

John JA, Draper NR (1980) An alternative family of transformations. Appl Stat 29:190-197. doi: $10.2307 / 2986305$

Kleindienst S, Seidel M, Ziervogel K, et al (2015) Chemical dispersants can suppress the activity of natural oil-degrading microorganisms. Proc Natl Acad Sci 112:14900-14905. doi: 


\subsection{3/pnas.1507380112}

Lu L, Zhu L (2012) Effect of soil components on the surfactant-enhanced soil sorption of PAHs. J Soils Sediments 12:161-168. doi: 10.1007/s11368-011-0432-6

Lu XY, Zhang T, Fang HHP (2011) Bacteria-mediated PAH degradation in soil and sediment. Appl Microbiol Biotechnol 89:1357-1371. doi: 10.1007/s00253-010-3072-7

Marini M, Frapiccini E (2013) Persistence of polycyclic aromatic hydrocarbons in sediments in the deeper area of the Northern Adriatic Sea (Mediterranean Sea). Chemosphere 90:1839-1846. doi: 10.1016/j.chemosphere.2012.09.080

Mason OU, Scott NM, Gonzalez A, et al (2014) Metagenomics reveals sediment microbial community response to Deepwater Horizon oil spill. ISME J 8:1464-1475. doi: 10.1038/ismej.2013.254

Matthies M (2011) Handbook of chemical mass transport in the environment, Toxicological \& Environmental Chemistry, 93:6, 1274-1275, doi: 10.1080/02772248.2011.585777

Mearns AJ, Reish DJ, Oshida PS, Ginn T (2010) Effects of pollution on marine organisms. Water Environ Res 82:2001-2046. doi: 10.2175/106143010X12756668802175

Office of Solid Waste (2008) Polycyclic Aromatic Hydrocarbons (PAHs). U.S. Environmental Protection Agency, Washington, DC, USA

Passow U (2016) Formation of rapidly-sinking, oil-associated marine snow. Deep Sea Res Part II Top Stud Oceanogr 129:232-240. doi: 10.1016/j.dsr2.2014.10.001

Perez Calderon LJ, Potts LD, Cornulier T, et al (2018a) The effect of chemical dispersant concentration on hydrocarbon mobility through permeable North-East Scotland sands. Estuar Coast Shelf Sci 214:72-81. doi: 10.1016/j.ecss.2018.09.008

Perez Calderon LJ, Potts LD, Gontikaki E, et al (2018b) Bacterial community response in deep FaroeShetland Channel sediments following hydrocarbon entrainment with and without dispersant addition. Front Mar Sci 5:. doi: 10.3389/fmars.2018.00159

Perez Calderon LJ, Vossen K, Potts LD, et al (2018c) Advective pore-water transport of hydrocarbons in North East Scotland coastal sands. Environ Sci Pollut Res 25:28445-28459. doi: $10.1007 / \mathrm{s} 11356-018-2815-3$

Piatt JJ, Backhus DA, Capel PD, Eisenreich SJ (1996) Temperature-dependent sorption of naphthalene, phenanthrene, and pyrene to low organic carbon aquifer sediments. Environ Sci Technol 30:751760. doi: 10.1021/es9406288

Pietroski JP, White JR, DeLaune RD (2015) Effects of dispersant used for oil spill remediation on nitrogen cycling in Louisiana coastal salt marsh soil. Chemosphere 119:562-567. doi: 10.1016/j.chemosphere.2014.07.050

Pignatello JJ (1998) Soil organic matter as a nanoporous sorbent of organic pollutants. Adv Colloid Interface Sci 76-77:445-467. doi: 10.1016/S0001-8686(98)00055-4

Prince RC (2015) Oil spill dispersants: boon or bane? Environ Sci Technol 49:6376-6384. doi: 10.1021/acs.est.5b00961 
R Development Core Team (2017) R: A language and environment for Statistical computing. R Found. Stat. Comput.

Reed M, Johansen Ø, Brandvik PJ, et al (1999) Oil spill modeling towards the close of the 20th century: overview of the state of the art. Spill Sci Technol Bull 5:3-16. doi: 10.1016/S13532561(98)00029-2

Rochelle-Newall EJ, Mari X, Pringault O (2010) Sticking properties of transparent exopolymeric particles (TEP) during aging and biodegradation. J Plankton Res 32:1433-1442. doi: 10.1093/plankt/fbq060

Seth R, Mackay D, Muncke J (1999) Estimating the organic carbon partition coefficient and its variability for hydrophobic chemicals. Environ Sci Technol 33:2390-2394. doi: $10.1021 / \mathrm{es} 980893 \mathrm{j}$

Webster L, Russell M, Walsham P, et al (2016) Determination and Environmental Assessment of Hydrocarbons in Water Samples Following a Release of Oil from the Clair Platform. Scottish Mar Freshw Sci 7:1-28. doi: 10.7489/1878-1

White HK, Lyons SL, Harrison SJ, et al (2014) Long-Term Persistence of Dispersants following the Deepwater Horizon Oil Spill. Environ Sci Technol Lett 1:295-299. doi: 10.1021/ez500168r

Wickham H, Chang W (2009) ggplot2: elegant graphics for data analysis

Xing B, Pignatello JJ, Gigliotti B (1996) Competitive sorption between atrazine and other organic compounds in soils and model sorbents. Environ Sci Technol 30:2432-2440. doi: $10.1021 / \mathrm{es} 950350 \mathrm{z}$

Yamada M, Takada H, Toyoda K, et al (2003) Study on the fate of petroleum-derived polycyclic aromatic hydrocarbons (PAHs) and the effect of chemical dispersant using an enclosed ecosystem, mesocosm. Mar Pollut Bull 47:105-113. doi: 10.1016/S0025-326X(03)00102-4

Zhao X, Gong Y, O'Reilly SE, Zhao D (2015) Effects of oil dispersant on solubilization, sorption and desorption of polycyclic aromatic hydrocarbons in sediment-seawater systems. Mar Pollut Bull 92:160-169. doi: 10.1016/j.marpolbul.2014.12.042

Zhao X, Liu W, Fu J, et al (2016) Dispersion, sorption and photodegradation of petroleum hydrocarbons in dispersant-seawater-sediment systems. Mar Pollut Bull 109:526-538. doi: 10.1016/j.marpolbul.2016.04.064

\section{Tables}

Table 1. Carbon content (total (TC), organic (TOC) and inorganic (TIC)) and particle size distribution of sediments used in sorption experiments. Average percentages are expressed in terms of mass and errors refer to standard deviation $(n=3)$.

\begin{tabular}{lccccrr}
\hline Station & TC (\%) & TIC (\%) & TOC (\%) & Sand (\%) & \multicolumn{1}{c}{ Silt (\%) } & Clay (\%) \\
\hline FSC & $2.164 \pm 0.028$ & $0.490 \pm 0.009$ & $1.674 \pm 0.019$ & $29.3 \pm 4.2$ & $65.5 \pm 4.4$ & $5.3 \pm 2.4$ \\
SB & $1.014 \pm 0.027$ & $0.040 \pm 0.080$ & $0.977 \pm 0.103$ & $95.6 \pm 1.2$ & $3.7 \pm 1.0$ & $0.7 \pm 0.2$
\end{tabular}




\section{$570 \quad 8 \quad$ Figure captions}

571 Fig. 1. Sampling locations of sediments used in sorption experiments from the Faroe-Shetland Channel 572 (FSC, yellow pin), Ythan estuary (YE, red pin) and Stonehaven Bay (SB, green pin).

573 Fig. 2. Effect of Superdispersant-25 on artificial seawater surface tension. Circles and crosses represent 574 values below and above the change in slope. The solid and dashed lines represent models before and 575 after slope change. The solution for the intersection of the two equations is the CMC the critical micelle 576 concentration of Superdispersant-25 $\left(4.63 \mathrm{mg} \mathrm{l}^{-1}\right)$. Grey bands represent standard error of linear models. 577 Note SD25 concentration has been $\log (x+1)$ transformed.

578 Fig. 3. Effect of initial Superdispersant-25 concentration in seawater ([SD25] $]_{\mathrm{Sw}, 0}$ ) on PAH solubility in artificial seawater $(S=34)$. Circles and crosses represent concentrations of naphthalene and phenanthrene, respectively. Solid and dashed lines, and grey bands represent locally weighted smooth regression predicted values and standard errors for naphthalene and phenanthrene, respectively.

Fig. 4. Superdispersant-25 uptake $\left(Q_{\mathrm{SD} 25}\right)$ onto sediments from the Faroe-Shetland Channel $(70.8 \%$ fines), Stonehaven Bay (4.4\% fines) and Ythan Estuary (0\% fines) as a function of initial Superdispersant- 25 concentration in seawater ([SD25] $]_{\mathrm{sw}, 0}$ ). Circles and crosses represent adsorption and desorption steps, respectively. Solid and dashed lines, and grey bands represent locally weighted smooth regression predicted values and standard errors for adsorption and desorption isotherms, respectively.

Fig. 5. Effect of sediment Superdispersant-25 concentration $\left(Q_{\mathrm{SD} 25}\right)$ on the distribution coefficient $\left(K_{\mathrm{D}}\right)$ of naphthalene and phenanthrene in sediments from the Faroe-Shetland Channel (70.8\% fines), Stonehaven Bay (4.4\% fines) and Ythan Estuary (0\% fines). Circles and crosses represent adsorption and desorption steps, respectively. Solid and dashed lines, and grey bands represent locally weighted smooth regression predicted values and standard errors for adsorption and desorption isotherms, respectively. Note the log-scale in the y-axis.

Fig. 6. Effect of sediment uptake of Superdispersant-25 $\left(Q_{\mathrm{SD} 25}\right)$ on the distribution coefficient $\left(K_{\mathrm{SD} 25}\right)$ of naphthalene and phenanthrene to sediment-adsorbed Superdispersant-25 surfactants in sediments from the Faroe-Shetland Channel (70.8\% fines), Stonehaven Bay (4.4\% fines) and Ythan Estuary (0\% fines). Circles and crosses represent adsorption and desorption steps, respectively. Solid and dashed lines, and grey bands represent locally weighted smooth regression predicted values and standard errors for adsorption and desorption isotherms, respectively. Y-axis scaling is log-modulus transformed to facilitate visualisation (John and Draper 1980). 